Article

\title{
Structure-Activity Relationship of Hydroxycinnamic Acid Derivatives for Cooperating with Carnosic Acid and Calcitriol in Acute Myeloid Leukemia Cells
}

\author{
Aviram Trachtenberg ${ }^{1} \mathbb{D}$, Katarzyna Sidoryk ${ }^{2} \mathbb{D}$, Somaya Alreate ${ }^{1} \mathbb{D}$, Suchismita Muduli $^{1}$, Andrzej Leś ${ }^{3}$, \\ Marcin Cybulski ${ }^{2}$ and Michael Danilenko ${ }^{1, *(\mathbb{D}}$
}

1 Department of Clinical Biochemistry and Pharmacology, Faculty of Health Sciences, Ben-Gurion University of the Negev, Beer Sheva 8410501, Israel; aviramtr@post.bgu.ac.il (A.T.); alreates@post.bgu.ac.il (S.A.); muduli@post.bgu.ac.il (S.M.)

2 Team of Chemistry, Department of Pharmacy, Cosmetic Chemicals and Biotechnology, Łukasiewicz Research Network-Industrial Chemistry Institute, 01-793 Warsaw, Poland; sidorykk@gmail.com (K.S.); marcin.cybulski@ichp.pl (M.C.)

3 Faculty of Chemistry, University of Warsaw, 02-093 Warsaw, Poland; ales@tiger.chem.uw.edu.pl

* Correspondence: misha@bgu.ac.il; Tel.: +972-8-647-9979

Citation: Trachtenberg, A.; Sidoryk, K.; Alreate, S.; Muduli, S.; Leś, A.; Cybulski, M.; Danilenko, M. Structure-Activity Relationship of Hydroxycinnamic Acid Derivatives for Cooperating with Carnosic Acid and Calcitriol in Acute Myeloid Leukemia Cells. Biomedicines 2021, 9, 1517. https://doi.org/10.3390/ biomedicines 9111517

Academic Editor: Sathish

Kumar Natarajan

Received: 15 July 2021

Accepted: 16 October 2021

Published: 21 October 2021

Publisher's Note: MDPI stays neutral with regard to jurisdictional claims in published maps and institutional affiliations.

Copyright: (c) 2021 by the authors. Licensee MDPI, Basel, Switzerland. This article is an open access article distributed under the terms and conditions of the Creative Commons Attribution (CC BY) license (https:/ / creativecommons.org/licenses/by/ $4.0 /)$.

\begin{abstract}
Plant phenolic compounds have shown the ability to cooperate with one another at low doses in producing enhanced anticancer effects. This may overcome the limitations (e.g., poor bioavailability and high-dose toxicity) in developing these agents as cancer medicines. We have previously reported that the hydroxycinnamic acid derivative (HCAD) methyl-4-hydroxycinnamate and the phenolic diterpene carnosic acid (CA) can synergistically induce massive calcium-dependent apoptosis in acute myeloid leukemia (AML) at non-cytotoxic concentrations of each agent. Here, we explored the chemical nature of the synergy between HCADs and either CA, in inducing cytotoxicity, or the active metabolite of vitamin D (calcitriol), in enhancing the differentiation of AML cells. This was done by determining the structure-activity relationship of a series of hydroxycinnamic acids and their derivatives (methyl hydroxycinnamates and hydroxybenzylideneacetones) in combination with CA or calcitriol. The HCAD/CA synergy required the following critical structural elements of an HCAD molecule: (a) the para-hydroxyl on the phenolic ring, (b) the carbon C7-C8 double bond, and (c) the methyl-esterified carboxyl. Thus, the only HCADs capable of synergizing with CA were found to be methyl-4-hydroxycinnamate and methyl ferulate, which also most potently enhanced calcitriol-induced cell differentiation. Notably, the C7-C8 double bond was the major requirement for this HCAD/calcitriol cooperation. Our findings may contribute to the rational design of novel synergistically acting AML drugs based on prototype combinations of HCADs with other agents studied here.
\end{abstract}

Keywords: structure-activity relationship; hydroxycinnamates; carnosic acid; vitamin D; acute myeloid leukemia

\section{Introduction}

The utilization of small-molecule drugs of plant origin (e.g., paclitaxel, vinblastine, topotecan, etoposide, etc.) in the chemotherapy of solid malignancies and lymphoid leukemias illustrates the importance of phytochemicals for clinical oncology [1]. Plantderived polyphenols, such as curcumin (CUR), epigallocatechin gallate or resveratrol, have been widely investigated for the anti-cancer activity in both laboratory and clinical studies (see [2-6] for recent reviews). Polyphenols exert strong antiproliferative and cytotoxic effects on various malignant cells in culture by targeting multiple cellular pathways [7-11]. However, when applied alone these agents are usually effective at high micromolar concentrations (e.g., [12-14]). Furthermore, polyphenols have poor oral bioavailability and biodistribution, thus their pharmacological effects in rodent cancer models are often evident 
at doses incompatible with human use $[7,15]$. One approach to lower the pharmacologically effective concentrations of polyphenols and to reduce their possible side effects is to take advantage of the ability of these compounds to cooperate with other antitumor agents and also with one another in producing enhanced anticancer effects, as demonstrated in a number of studies conducted using various in-vitro and in-vivo models (e.g., [16-21]). For instance, we and others have shown that the phenolic diterpene carnosic acid (CA) and the polyphenols curcumin CUR and silibinin can strongly synergize with active vitamin D derivatives at low concentrations to exert enhanced cell differentiation and growth arrest in human [22-25] and murine [26,27] acute myeloid leukemia (AML) cell lines, and leukemic blasts from patients with AML $[28,29]$. Furthermore, combined treatment with a standardized CA-rich rosemary extract and low-calcemic vitamin $\mathrm{D}$ analogs resulted in a strong cooperative antileukemic effect in syngeneic mouse models of AML, without significant toxicity $[26,27]$. We have also reported that CUR and CA can strongly cooperate at low concentrations of each compound to synergistically induce robust calcium-mediated apoptosis in AML cells, but not in normal hematopoietic cells, and to inhibit disease progression in a xenograft mouse model of AML [30,31].

Hydroxycinnamic acids, e.g., para-coumaric (4-hydroxycinnamic), ferulic and caffeic acids, as well as their derivatives (HCADs) are naturally occurring phenolic compounds synthesized by various plants and mushrooms from the amino acid phenylalanine and are abundant in the diet [32]. The anti-cancer activities of HCADs have been recently reviewed $[33,34]$. Specifically, several studies demonstrated anti-leukemic effects of caffeic acid phenethyl ester, tetradecyl ester of para-coumaric acid and other HCADs on AML and lymphoid leukemia cells $[33,34]$. We have found that the HCAD methyl 4-hydroxycinnamate (MHC) is moderately cytotoxic to AML cells but, similar to CUR, can strongly cooperate at low concentrations with CA in inducing calcium-dependent apoptotic cell death. The synergy between MHC and CA was confirmed by combination index analysis [35]. The purpose of the present study was to characterize the structural requirements for MHC-like compounds to effectively cooperate with CA in inducing cytotoxicity and with the hormonal form of vitamin $\mathrm{D}, 1 \alpha, 25$-dihydroxyvitamin $\mathrm{D}_{3}$ (calcitriol), in potentiating cell differentiation. To do so, we investigated the structure-activity relationships of a series of related HCADs (compounds KS-1-KS-12) as well as free para-coumaric and ferulic acid (Figure 1) for their abilities to synergize with CA and calcitriol. The results demonstrated that the para position of the hydroxyl group on the phenolic ring, the C7-C8 double bond and the methyl-esterified carboxyl group, as in MHC (compound KS-3), are critical for the capacity of an HCAD molecule to synergize with CA. Furthermore, we found that the presence of additional groups on the phenolic ring, such as the methoxy group in methyl ferulate (compound KS-6) or hydroxyl groups in compounds KS-4 and KS-5 and methyl caffeate, interferes with this feature of HCADs. On the other hand, the capacity to enhance the prodifferentiation effect of calcitriol appeared to require mainly the existence of the $\mathrm{C} 7-\mathrm{C} 8$ double bond in the HCAD molecules. 
(a)

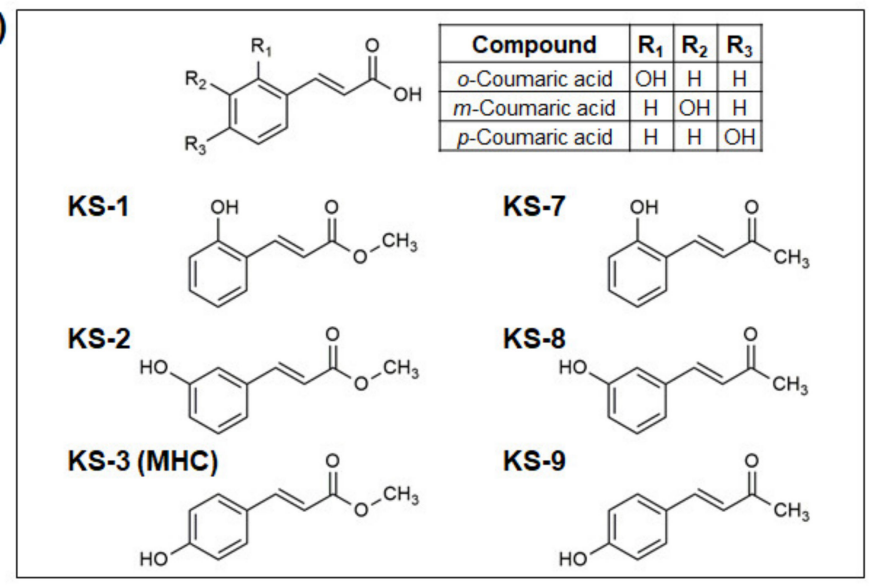

(b)

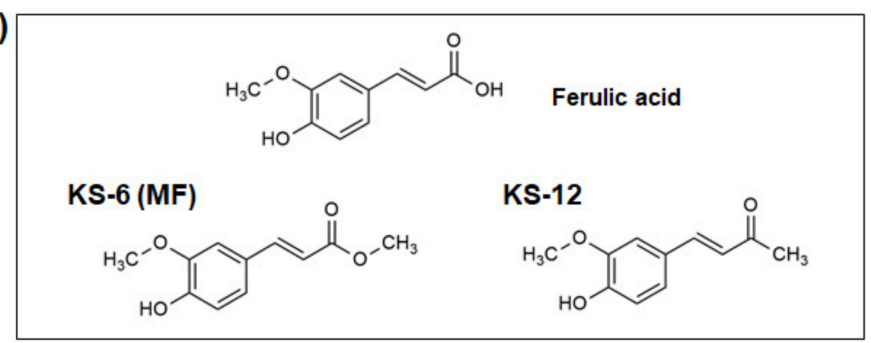

Figure 1. Molecular structures of coumaric and ferulic acids and their derivatives. (a) Ortho, meta and para coumaric acids and their derivatives methyl 2-hydroxycinnamate (KS-1), methyl 3-hydroxycinnamate (KS-2), methyl 4-hydroxycinnamate (KS-3), 2-hydroxybenzalacetone (KS-7), 3-hydroxybenzalacetone (KS-8) and 4-hydroxybenzalacetone (KS-9). (b) Ferulic acid and its derivatives methyl ferulate (KS-6) and 4-hydroxy-3-methoxybenzalacetone (KS-12).

\section{Materials and Methods}

\subsection{Materials}

Carnosic acid (98\%) was purchased from Chemlin UK (Nanjing, China). Para coumaric acid ( $\geq 98 \%$ ) was procured from Merck-Sigma-Aldrich (Rehovot, Israel). Ferulic acid ( $\geq 98 \%$ ) and fluo-3/AM were purchased from Santa Cruz Biotechnology (Dallas, TX, USA). Methyl 2-hydroxycinnamate (KS-1), methyl 3-hydroxycinnamate (KS-2), methyl 4-hydroxycinnamate (MHC; KS-3), methyl 2,4-dihydroxycinnamate (KS-4), methyl 2,3,4trihydroxycinnamate (KS-5), methyl ferulate (KS-6), 2-hydroxybenzylideneacetone (KS-7), 3-hydroxybenzylideneacetone (KS-8), 4-hydroxybenzylidenecetone (KS-9) and 4-hydroxy-3methoxybenzylideneacetone (KS-12) were synthesized and purified ( $96 \%$ ) by Dr. Katarzyna Sidoryk (Team of Chemistry, Łukasiewicz Research Network-Industrial Chemistry Institute, Warsaw, Poland), as described previously [36]. Methyl 4-hydroxycinnamate ( $\geq 98 \%)$ and methyl ferulate $(\geq 98 \%$ ) were purchased from Santa Cruz Biotechnology (Dallas, TX, USA). Methyl caffeate $(>98 \%)$ was acquired from Cayman Chemical (Ann Arbor, MI, USA). Methyl 4-hydroxybenzoate (MHB, 99\%) and methyl 3-(4-hydroxyphenyl)propionate (MHP, 98\%) were procured from Alfa Aesar (Haverhill, MA). Methyl 3-hydroxy-4-methoxybenzoate (MHMB, 98\%) and methyl 3-(3-hydroxy-4-methoxyphenyl)propanoate (MHMP, $\geq 95 \%$ ) were acquired from Merck-Sigma-Aldrich (Rehovot, Israel) and Activate Scientific (Littleport, UK), respectively. Annexin V-FITC/7-Aminoactinomycin D (7-AAD) Apoptosis Detection Kit (Biogems, Cat\# 62700-50, Annexin V FITC Apoptosis Detection Kit) was purchased from BioGems (Chai Wan, Hong Kong, China). Calcitriol (1 $1 \alpha, 25-$ dihydroxyvitamin $\mathrm{D}_{3} ;>99 \%$ ) was obtained from Selleck Chemicals (Houston, TX, USA). Mouse anti-Human CD11b (Beckman Coulter, Cat\# 6603573, RRID:AB_2890224), Lot\# 7012017, FITC conjugated IgM (clone 94), mouse anti-Human CD14 (Beckman Coulter, Cat\# 6603262, RRID:AB_2890223), Lot\# 7139028, RD1 conjugated, mouse IgG2b (clone 322A-1), mouse IgM, FITC conjugated (Beckman Coulter, Cat\# 6603877, RRID:AB_2890227), 
Lot\# 7284017 and, mouse IgG2b, RD1 conjugated (Beckman Coulter, Cat\# 6603852, RRID: AB_2890228), Lot\# 7301014 were purchased from Beckman Coulter (Fullerton, CA, USA). RPMI 1640 medium and heat-inactivated fetal bovine serum (FBS) were purchased from Gibco-Invitrogen (Carlsbad, CA, USA). Hank's buffered salt solution (HBSS), $\mathrm{Ca}^{2+} / \mathrm{Mg}^{2+}$ free phosphate buffered saline (PBS), L-glutamine, penicillin, streptomycin, and HEPES were purchased from Biological Industries (Beit Haemek, Israel). The stock solutions of carnosic acid $(10 \mathrm{mM})$ and calcitriol $(2.5 \mu \mathrm{M})$ were prepared in absolute ethanol. All other test agents were dissolved at $50 \mathrm{mM}$ in DMSO. The precise concentration of calcitriol in ethanol solutions was verified spectrophotometrically at $264 \mathrm{~nm}\left(\varepsilon=19,000 \mathrm{M}^{-1} \mathrm{~cm}^{-1}\right)$. The following solvents were used as vehicle controls: $\leq 0.1 \%$ DMSO or $\leq 0.1 \%$ ethanol for single treatments and $\leq 0.1 \% \mathrm{DMSO}+\leq 0.1 \%$ ethanol for combined treatments.

\subsection{Cell Culture and Enumeration}

Human KG-1a stem-like leukemia cells (Cat\# CCL-246.1, RRID:CVCL_1824), HL60 myoblastic cells (Cat\# CCL-240, RRID:CVCL_0002) and U937 myelomonocytic cells (Cat\# CRL-1593.2, RRID:CVCL_0007) were obtained from American Type Culture Collection (Rockville, MD). Cells were cultured in RPMI 1640 medium supplemented with 10\% FBS, L-glutamine $(2 \mathrm{mM})$, penicillin $(100 \mathrm{U} / \mathrm{mL})$, streptomycin $(0.1 \mathrm{mg} / \mathrm{mL})$, and $10 \mu \mathrm{M} \mathrm{HEPES}$ $\left(\mathrm{pH}=7.4\right.$ ) in a humidified atmosphere of $95 \%$ air and $5 \% \mathrm{CO}_{2}$, at $37{ }^{\circ} \mathrm{C}$. Routine testing for mycoplasma contamination was carried out once a month using a Myco-Blue Mycoplasma Detector (Vazyme Biotech Co. Ltd., Nanjing, China) according to the manufacturer's instructions. Briefly, cells were centrifuged at $500 \times g$ for $5 \mathrm{~min}$ in $1 \mu \mathrm{L}$ of the supernatant, the negative control (PCR-grade water) and positive control were mixed with Myco-Blue Enzyme $(1 \mu \mathrm{L})$ and MycoBlue Buffer $(24 \mu \mathrm{L})$, respectively, in separate PCR tubes. Samples were incubated at $60^{\circ} \mathrm{C}$ for $1 \mathrm{~h}$ and followed by color detection according to the instructions. For experiments, cells were seeded at a concentration of 1.0-2.5 × 10 $0^{5}$ cells $/ \mathrm{mL}$ in $24-$ or 6 well plates, for 8-72 h. Cells were enumerated in Vi-Cell XR cell viability analyzer (Beckman Coulter Vi-Cell XR cell counter (ISO 6 clean room) Vicell, RRID:SCR_019664) version\# 2.4 (Beckman Coulter, Fullerton, CA, USA) using an automatic trypan blue exclusion assay, as described previously [35]. The number of viable (trypan blue-impermeable) cells was counted directly. The percent of cell death was calculated as the number of dead (trypan blue-positive) cells relative to the total (viable + dead) cell count.

\subsection{Annexin V/7-Aminoactinomycin D Assay}

Cells $\left(3 \times 10^{5} / \mathrm{mL}\right)$ were washed with PBS and then stained with annexin V-APC and 7-AAD in binding buffer, as described previously [30,35]. Percentages of apoptotic cells were determined by flow cytometry in a Gallios instrument (Beckman Coulter Gallios Flow Cytometer, RRID:SCR_019639; Beckman Coulter, Miami, FL, USA). For each analysis, 10,000 events were recorded, and the data were processed using the Kaluza software (GalliosTM Kaluza, RRID:SCR_016700) version \#2.1 (Beckman Coulter, Miami, FL, USA). Annexin V-positive/7-AAD-negative cells were considered to be early apoptotic and cells positive for both annexin $\mathrm{V}$ and 7-AAD to be late-apoptotic.

\subsection{Determination of Cell Differentiation}

Cells were seeded at $5 \times 10^{4}$ cells $/ \mathrm{mL}$ and treated with test agents or vehicle $(\leq 0.2 \%$ ethanol $)$ for $96 \mathrm{~h}$. Aliquots of $5 \times 10^{5}$ cells were harvested, washed with PBS, and incubated for $45 \mathrm{~min}$ at room temperature with $0.3 \mu \mathrm{L}$ anti-human CD11b-FITC and $0.3 \mu \mathrm{L}$ anti-human CD14-RD1 to determine the expression of myeloid surface antigens CD11b and CD14, respectively, by flow cytometry as described previously [37,38]. For each analysis 10,000 events were recorded, and the data were analyzed using the Kaluza version \#2.1 software (Beckman Coulter, Miami, FL, USA). 


\subsection{Cytosolic Calcium Assay}

Steady state cytosolic $\mathrm{Ca}^{2+}$ levels were determined as described previously $[30,35]$. Briefly, cells $\left(5 \times 10^{5} / \mathrm{mL}\right)$ were preloaded with the calcium-sensitive fluorescence indicator Fluo-3/ AM $(2.5 \mu \mathrm{M})$ in $\mathrm{CaCl}_{2}(2 \mathrm{mM})$-supplemented Ringer's solution, for $30 \mathrm{~min}$ at room temperature in the dark. Cells were then washed with $\mathrm{Ca}^{2+-}$ free Ringer's solution and resuspended in the same buffer. Flow cytometric measurement of Fluo-3 fluorescence was performed within $1 \mathrm{~min}$ of adding test compounds to the cell suspension. The data are expressed as the geometric mean Fluo-3 fluorescence intensity (MFI).

\subsection{Western Blot Analysis}

Western blotting was performed using whole cell extracts, as described previously [35]. Briefly, cells were lysed in ice-cold lysis buffer containing $50 \mathrm{mM}$, HEPES (pH 7.5), $150 \mathrm{mM}$ $\mathrm{NaCl}, 10 \%(v / v)$ glycerol, $1 \%(v / v)$ Triton $\mathrm{X}-100,1.5 \mathrm{mM}$ EGTA, $2 \mathrm{mM}$ sodium orthovanadate, $20 \mathrm{mM}$ sodium pyrophosphate, $50 \mathrm{mM} \mathrm{NaF}, 1 \mathrm{mM}$ DTT and 1:50 Complete ${ }^{\mathrm{TM}}$ proteaseinhibitors cocktail (Roche Molecular Biochemicals, Mannheim, Germany) and centrifuged at 20,000 $\times g, 10 \mathrm{~min}, 4^{\circ} \mathrm{C}$. Supernatant samples (10-30 $\mu \mathrm{g}$ protein) were subjected to SDSPAGE and then electroblotted into a nitrocellulose membrane (Whatman, Dassel, Germany). The membranes were blocked with $5 \%$ milk for $1 \mathrm{~h}$ and incubated with primary antibodies overnight at $4{ }^{\circ} \mathrm{C}$ followed by incubation with HRP-conjugated secondary antibodies antirabbit (Jackson ImmunoResearch Laboratories, Inc., West Grove, PA, USA) and anti-mouse (GE Healthcare, Pittsburgh, PA, USA) for $1 \mathrm{~h}$. The protein bands were visualized using the WESTAR ECL HRP substrate (CYANAGEN, Bologna, Italy). The following primary antibodies were used: caspase-3 (Santa Cruz Biotechnology Cat\# sc-7272, RRID:AB_626803; 1:500), Lot\# J219 from Santa Cruz Biotechnology (Santa Cruz, CA, USA); cleaved caspase3 (Cell Signaling Technology Cat\# 9661, RRID:AB_2341188; 1:1000), Lot\# 45 from Cell Signaling Technology (Danvers, MA, USA) and poly(ADP-ribose) polymerase (PARP) (Enzo Life Sciences Cat\# BML-SA253, RRID:AB_2283566; 1:5000), Lot\# 10021421 from Enzo Life Sciences (Farmingdale, NY, USA).

\subsection{Molecular Modeling of the Formation of CA Anion-HCAD Complexes}

The quantum mechanical density functional theory (DFT) calculations with the B3LYP functional and the 6-31G(d,p) Gaussian basis set with the Grimme's empirical dispersion correction [39] was used for modeling of the 3D molecular structure of the complexes formed by carnosic acid CA anions and selected HCAD molecules (KS-1, KS-3, KS-7 and KS-9). The optimization of the molecular structures was performed with the Berny's optimization algorithm. All the calculations were done at the Interdisciplinary Centre for Mathematical and Computational Modelling (ICM, University of Warsaw). The intermolecular interaction energy or the binding energy (BE) was estimated with the following formula:

$$
\mathrm{BE}=\mathrm{E}(\text { complex })-\{\mathrm{E}(\text { carnosic acid anion })-\mathrm{E}(\mathrm{KS}-\mathrm{x})\}
$$

where $\mathrm{E}$ denotes the DFT energy and $\mathrm{x}=1,3,7,9$. The binding energy was calculated according to the method usually applied for the calculations of the intermolecular interaction energy with the correction known as the basis set superposition error or the counterpoise correction [40]. Such a correction originates from the fact that a more realistic estimation of the intermolecular interaction energy can be obtained when the energy of each component of the complex is calculated with the use of the atomic basis set of the entire complex.

\subsection{Statistical Analysis}

All experiments were conducted at least three times. The number of independent experiments $(n)$ is indicated in the legends to figures. Statistically significant differences between two experimental groups were estimated by the unpaired two-tailed Student's $t$ test. The significance of the differences between the means of several subgroups was assessed by one-way ANOVA with Tukey's or Dunnett's multiple comparison post-hoc 
analysis. $p$ values less than 0.05 were considered statistically significant. The synergy between the effects of two compounds was determined as described previously $[24,35]$. Briefly, two compounds (A and B) were considered to show enhancement in the particular experiment if the effect of their combination $(\mathrm{AB})$ was larger than the sum of their individual effects $(\mathrm{AB}>\mathrm{A}+\mathrm{B})$, the data being compared after subtraction of the respective control values from $A, B$ and $A B$. The statistical analyses were performed using GraphPad Prism 6.0 software (GraphPad Software, San Diego, CA, USA).

\section{Results}

3.1. Essential Structural Features of Hydroxycinnamic Acid Derivatives Required for the Synergy with Carnosic Acid in Inducing Cytotoxicity to AML Cells

In order to determine the structural requirements of HCADs for the cooperation with CA, we synthesized two series of coumaric and ferulic acid derivatives: methyl hydroxycinnamates and hydroxybenzylideneacetones.

Both series of coumaric acid derivatives included compounds with a hydroxyl group at the ortho (KS-1 and KS-7), meta (KS-2 and KS-8) or para (KS-3/MHC and KS-9) positions of the phenolic ring (Figure 1a). Ferulic acid derivatives were represented by methyl hydroxycinnamate/methyl ferulate (KS-6) and hydroxybenzylideneacetone (KS-12), as shown in Figure 1b. We first tested these HCADs, as well as free para-coumaric acid (pCouA) and ferulic acid (FerA) for the antiproliferative/cytotoxic activity in KG-1a cells. For this purpose, cells were incubated with each compound at $5-25 \mu \mathrm{M}$, for $72 \mathrm{~h}$, followed by cell enumeration using the Trypan Blue exclusion assay.

As shown in Figure 2a, all the tested compounds were capable of reducing the number of viable cells in a concentration-dependent manner to a varying extent. KS-7 was found to be the most potent agent, whereas the maximal inhibitory effects of KS-1, pCouA and FerA did not exceed $10-15 \%$. Of all the above compounds, only KS-3 and KS-7 exhibited mild-tomoderate cytotoxicity, as indicated by an increase in the percent of cell death (Figure $2 b$ ). Cytotoxicity of the rest of the single agents was $\leq 5 \%$ even at the highest concentration tested $(25 \mu \mathrm{M})$.

To explore whether, similar to KS-3/MHC [35], other structurally related HCADs can cooperate with CA (Figure 2c), we counted KG-1a and HL60 cells following the exposure to the synthesized compounds (KS-1-KS-12), pCouA and FerA at their lowest tested concentration ( $5 \mu \mathrm{M}$; Figure $2 \mathrm{a}, \mathrm{b})$ and $\mathrm{CA}$ at the non-cytotoxic concentration of $10 \mu \mathrm{M}[30,31,35]$, alone and in combination, for $72 \mathrm{~h}$. Surprisingly, the results demonstrated that, besides KS-3/MHC, only KS-6/MF was able to synergize with CA in reducing the number of viable AML cells (Figure 2d,e). Still, the KS-3+CA combination was found to be significantly more effective than KS-6+CA. Likewise, only these two combinations were capable of inducing apoptosis in KG-1a and HL60 cells, as evidenced by caspase-3 and PARP cleavage (Figure 2f).

We have previously reported that apoptosis induction by both CUR+CA and MHC/KS$3+\mathrm{CA}$ is mediated by intracellular calcium mobilization [30,35]. Here, we confirmed that distinct pro-apoptotic features of the KS-3/CA and KS-6/CA combinations were associated with their significant capacity to induce a rapid elevation of the cytosolic $\mathrm{Ca}^{2+}$ levels in both KG-1 (Figure 3a,b) and HL60 (Figure 3c,d) cells, whereas the other tested HCAD/CA combinations produced only a minor or no effect. These experiments again demonstrated that KS-3+CA was more effective, compared with KS-6+CA (Figure 3b,d).

Further comparison between the two combinations revealed that KS-3+CA was also more efficient than KS-6+CA in inducing apoptosis, as indicated by higher levels of annexinV /7-AAD binding (Figure 4a,b), caspase-3 and PARP cleavage (Figure 4c) and blebbing or shrinkage of acridine orange/ethidium bromide-stained nuclei (Suppl. Figure S1) in KS-3+CA-treated cells. These effects were both cell type- and time-dependent. Particularly, in KG-1a cells, marked increases in the above apoptotic markers were evident as early as at $8 \mathrm{~h}$ (Figure $4 \mathrm{a}-\mathrm{c}$ and Suppl. Figure S1a,c) while practically no such increases were observed at this time point in HL60 cells (Figure 4b,c and Suppl. Figure S1d,f). 
(a)

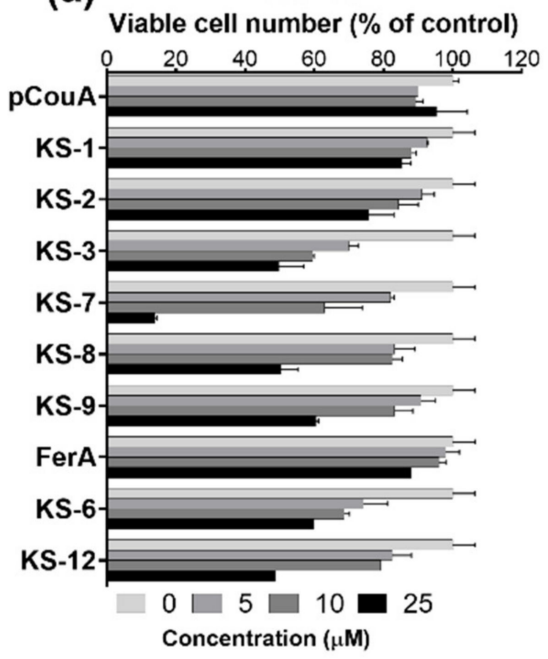

(d)

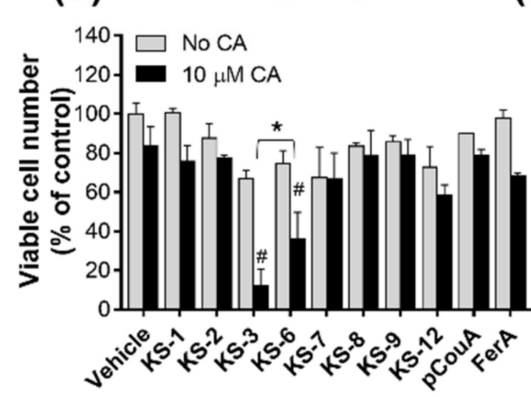

(b)

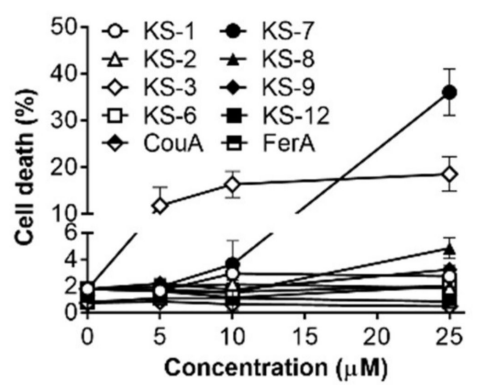

(c)

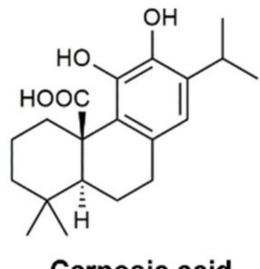

Carnosic acid

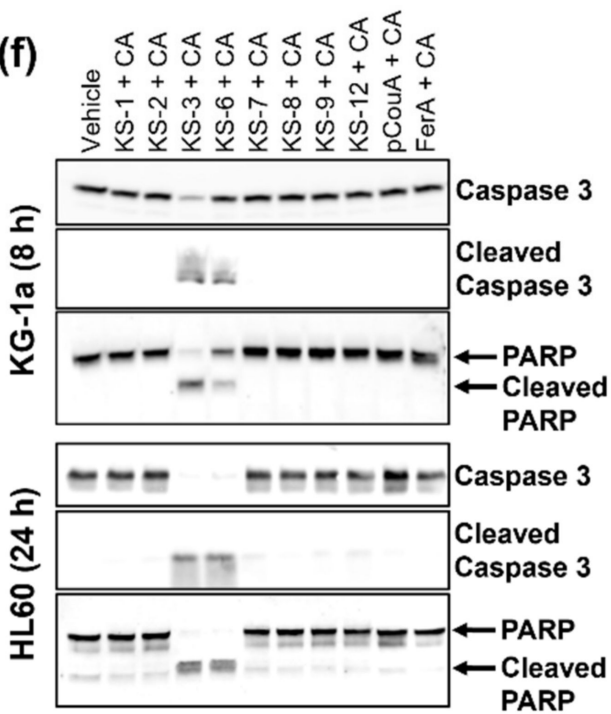

Figure 2. The hydroxycinnamic acid derivatives methyl 4-hydroxycinnamate (KS-3) and methyl ferulate (KS-6), but not their chemical analogs, synergize with carnosic acid in inducing cytotoxicity to AML cells. KG-1a and HL60 cells were treated with $5 \mu \mathrm{M}$ para-coumaric acid (pCouA), ferulic acid (FerA) or their derivatives, $10 \mu \mathrm{M}$ carnosic acid (CA), alone or in combination followed by the Trypan Blue exclusion assay $(72 \mathrm{~h} ;(\mathbf{a}, \mathbf{b}, \mathbf{d}, \mathbf{e}))$ or Western blot analysis $(8 \mathrm{~h}$ and $24 \mathrm{~h} ;(\mathbf{f}))$. $(\mathbf{a}, \mathbf{b})$ Effects of the indicated compounds on the number of viable cells (a) and the percent of cell death (b) in KG-1a cell cultures. $(\mathbf{a}, \mathbf{b})$ The data are the means $\pm \mathrm{SD}(n=3)$. (c) The molecular structure of carnosic acid. (d,e) Effects of the indicated compounds on the number of viable cells of KG-1a (d) and HL60 (e) cells. (d,e) The data are the means \pm SD ( $n=3-6)$. $*, p<0.05$, significant difference between the KS-3+CA and KS-6+CA groups. \#, $p<0.05$, effect of a combination vs. sum of the effects of single agents $(n=6)$; Student's $t$ test. (f) Caspase- 3 and PARP cleavage in KG-1a and HL60 cells following treatment with the indicated combinations of pCouA, FerA or their derivatives, together with CA.

Collectively, the above data indicate that the para position of a hydroxyl group on the phenolic ring and modification of the carboxyl group to methyl ester, but not methyl ketone, are essential structural requirements allowing coumaric and ferulic HCADs to effectively cooperate with CA in inducing apoptosis in AML cells. Further, these results imply that the presence of other chemical substituents on the KS-3 phenolic ring in addition to the para-OH, e.g., the meta-methoxy group as in KS-6, may interfere with the capability of HCADs to synergize with CA. To test this hypothesis, we examined cytotoxicity of methyl caffeate whose phenolic ring contains meta-hydroxyl besides para-hydroxyl (Suppl. Figure S2a) and newly synthesized KS-3-like compounds in which ortho hydroxyl (KS-4) or both ortho and meta hydroxyls (KS-5) were added (Figure 5a). When applied at 5-25 $\mu \mathrm{M}$ to KG-1a cells for $72 \mathrm{~h}$, the three compounds reduced cell number/viability to varying extents (Suppl. Figure S2b and Figure 5b,c). Yet, in contrast to KS-3, none of these agents was capable of synergizing with CA, as determined by the ATP-based cell viability assay (Suppl. Figure S2c,d), Trypan Blue exclusion assay (Figure $5 \mathrm{~d}, \mathrm{e}, \mathrm{g}, \mathrm{h}$ ) or annexin-V/7-AAD assay (Figure 5f,i) in KG-1a cells (Figure 5d,e,f) and HL60 cells (Figure 5g,h,i). Taken together, 
the above results support the notion that additional groups on the phenolic ring of KS-3 impair or abolish its ability to cooperate with CA.

(a)

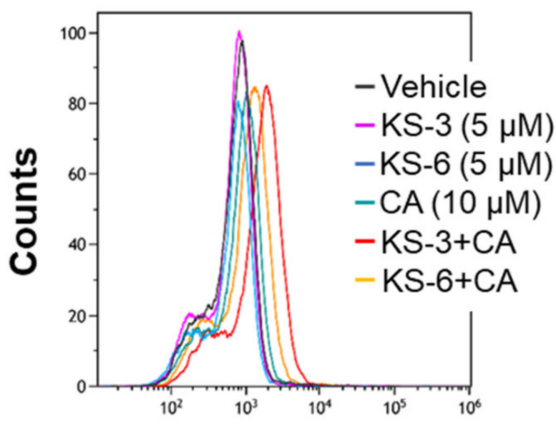

Fluo-3 fluorescence

(c)

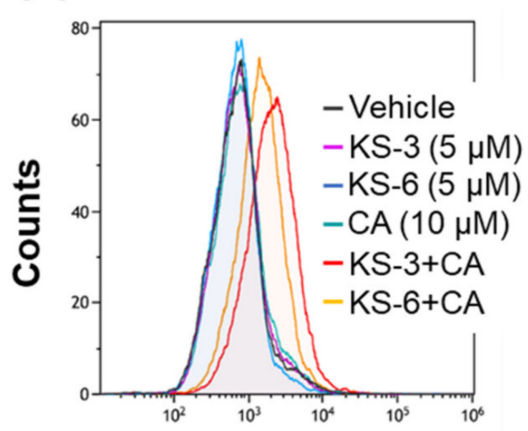

Fluo-3 fluorescence (b)

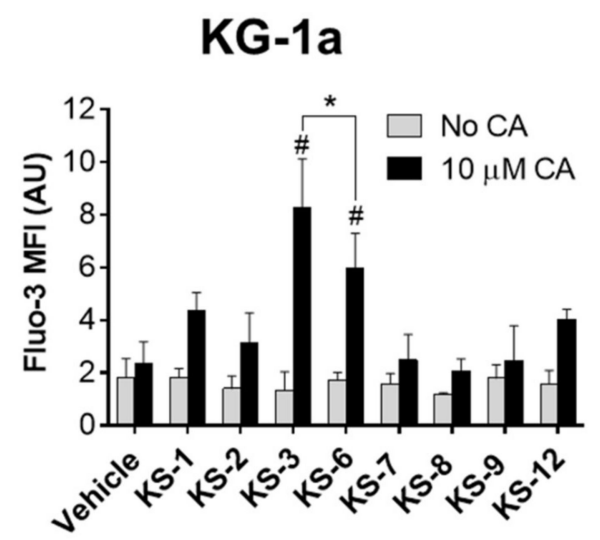

(d)
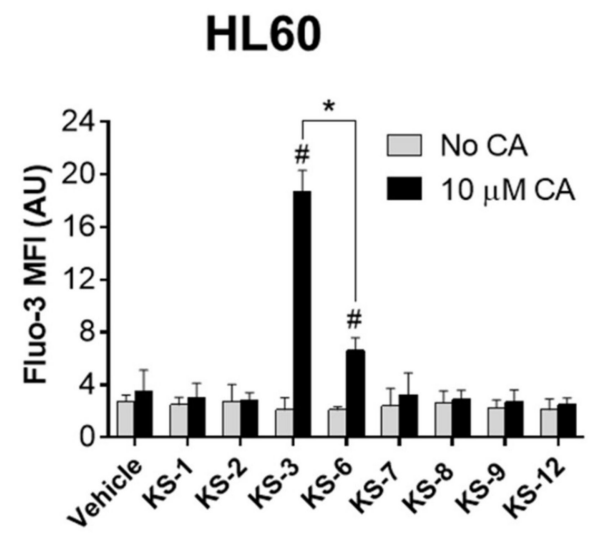

Figure 3. KS-3 and KS-6, but not their chemical analogs, synergize with carnosic acid in inducing a rapid elevation of cytosolic $\mathrm{Ca}^{2+}$ levels in AML cells. KG1a and HL60 cells were treated with $5 \mu \mathrm{M}$ of the indicated hydroxycinnamic acid derivatives, $10 \mu \mathrm{M}$ carnosic acid (CA) or their combinations for $10 \mathrm{~s}$, followed by determination of Fluo-3 fluorescence by flow cytometry. (a,c) Typical flow cytometric data of Fluo-3 fluorescence obtained in representative experiments. (b,d) Averaged Fluo-3 geometric mean fluorescence intensity (MFI) $\pm \mathrm{SD}(n=5){ }^{*}, p<0.05$, significant difference between the KS-3+CA and KS-6+CA groups. \#, $p<0.05$, effect of a combination vs. sum of the effects of single agents; one-way ANOVA with Dunnett's post-hoc analysis.

To examine the role of the $\alpha, \beta$-unsaturated carbonyl moieties of KS- 3 and KS- 6 in this cooperation, we compared the effects of the two HCADs (Figure 6a) and their analogs that have a saturated C7-C8 bond (methyl [3-(4-hydroxyphenyl)] propionate [MHP] and methyl 3-[(3-hydroxy-4-methoxyphenyl)]propanoate [MHMP]) or a truncated side chain (methyl 4hydroxybenzoate [MHB] and methyl 3-hydroxy-4-methoxybenzoate [MHMB]) (Figure 6a). Remarkably, none of these modified compounds, applied at $5 \mu \mathrm{M}$, either alone or together with CA, was able to significantly reduce viable cell numbers (Figure 6b), increase the percent of cell death (Figure $6 \mathrm{c}$ ) or induce apoptosis (Figure $6 \mathrm{~d}$ ). These results suggest that the C7-C8 double bond of an HCAD is also critical for the cooperation with CA. 
(a)
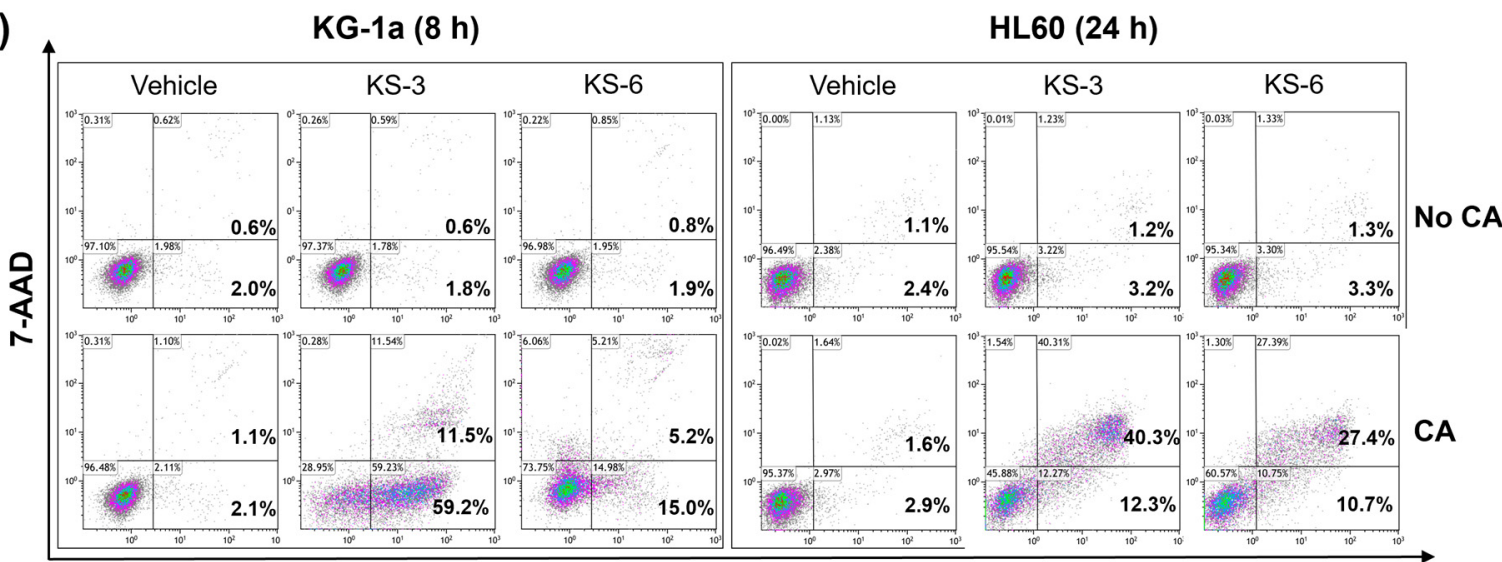

(b)

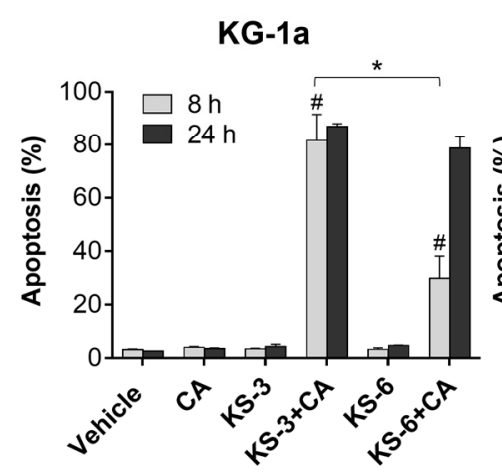

Annexin V-APC

(c)

HL60

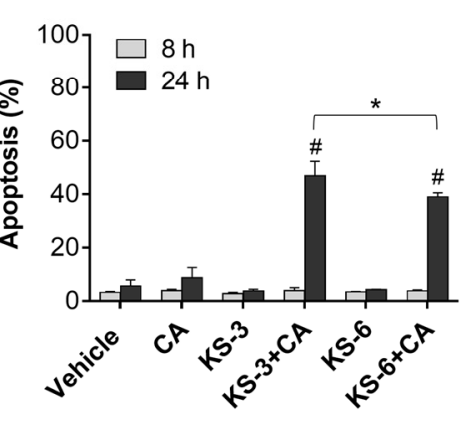

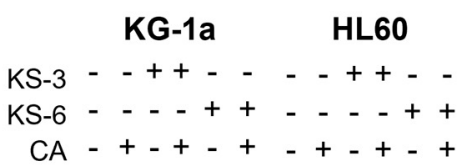

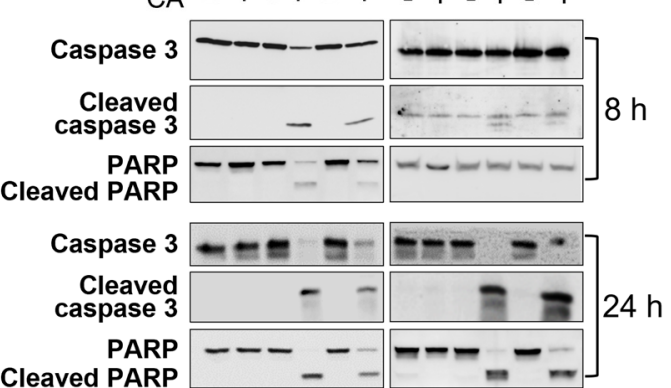

Figure 4. Comparison between the apoptosis-inducing effects of the combinations of KS-3 and KS-6 with carnosic acid. KG-1a and HL60 cells were cultured with $5 \mu \mathrm{M}$ KS-3 or KS-6, $10 \mu \mathrm{M}$ carnosic acid (CA) or their combinations, for 8 or $24 \mathrm{~h}$. The extent of apoptosis was determined by the annexin V/7-AAD binding assay or Western blotting. (a) Typical flow cytometric data obtained in representative experiments. (b) Averaged percentages of apoptotic (early + late) cells as exemplified in panel (a). The data are the means $\pm \operatorname{SD}(n=5) .{ }^{*}, p<0.05$, significant differences between the indicated groups; Student's $t$ test. \#, $p<0.05$, effect of a combination vs. sum of the effects of single agents; Student's $t$ test. (c) Caspase-3 and PARP cleavage in KG-1a and HL60 cells following treatment with KS-3 or KS-6, alone or together with CA.

\subsection{Molecular Modeling of the Formation of HCAD … CA Anion Complexes}

Since the above in vitro experiments demonstrated that among all the tested HCADs only KS-3 and, to a lesser extent, KS-6 could synergize with CA, we next explored the potential for a direct intermolecular interaction between KS-3 or KS-6 and the CA anion using in-silico molecular modeling. Three other KS compounds (KS-1, KS-7, and KS-9), which were unable to cooperate with CA in AML cell cultures, were used as negative controls in the modeling studies.

The molecular structures of the five putative complexes appeared to have closed forms where both components are positioned almost parallel to each other (Figure 7). Their 3D structures are visible with the use of molecular graphics software (e.g., RasMol, Jmol) based on the Cartesian coordinates available in the Supporting Information (Suppl. Table S1). One can see that no intermolecular hydrogen bonds appear, in contrary to a strong intramolecular $\mathrm{H}$-bond in the $\mathrm{CA}$ anion between the $\mathrm{COO}^{-}$and $-\mathrm{OH}$ groups. This $\mathrm{H}$-bond is better described as an interaction between $\mathrm{COOH}$ and $\mathrm{O}^{-}$resulting from the proton transfer, as it is seen in Figure 7a-e. The geometry of the KS-CA anion molecular complexes is reminiscent of a half-opened oyster. The angle between the aromatic ring of the KS molecule and of the CA anion is about $44^{\circ}-45^{\circ}$ degrees. 
(a)<smiles>COC(=O)/C=C/c1ccc(O)cc1/C=C/C(=O)OC</smiles>

(d)

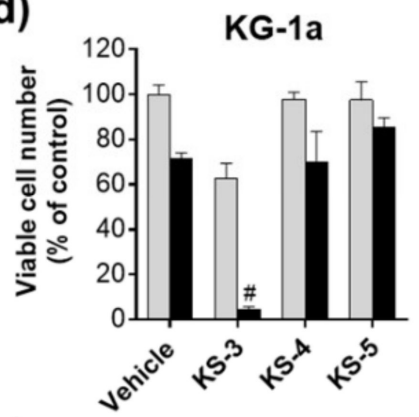

(g)

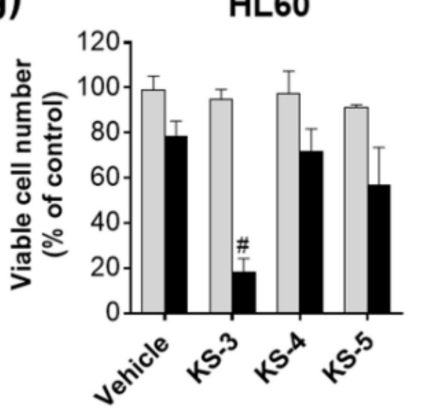

(b)

KG-1a

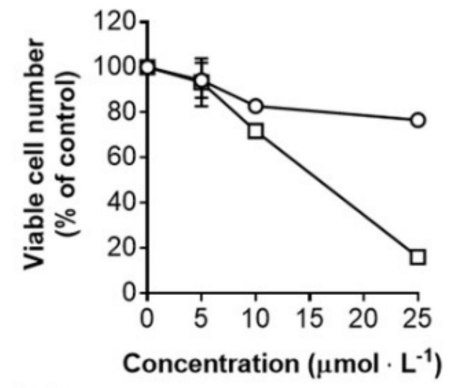

(e)

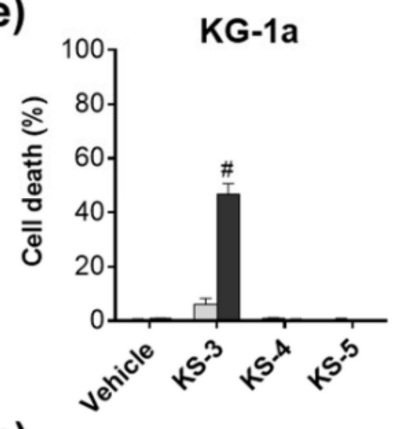

(h)

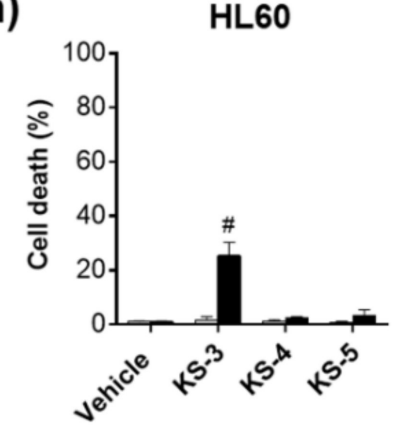

(c) KG-1a

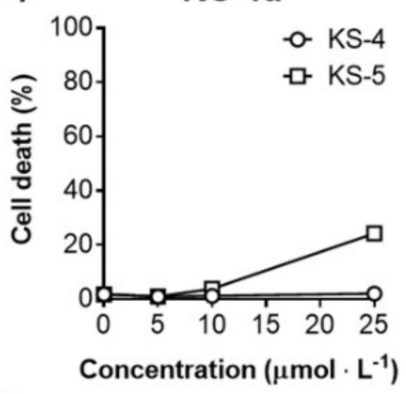

(f)

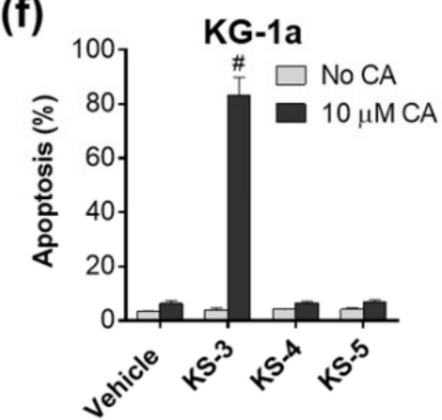

(i)

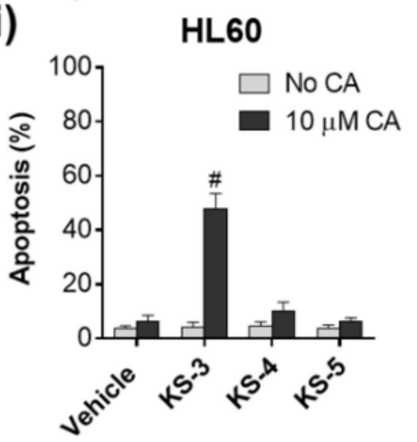

Figure 5. Additional hydroxyl groups on the phenolic ring of KS-3 impair its ability to cooperate with carnosic acid. (a) Molecular structures of methyl 3-(2,4-dihydroxyphenyl)acrylate (KS-4) and (E)-methyl 3-(2,3,4-trihydroxyphenyl)acrylate (KS-5). (b,c) Concentration-dependent effects of KS-4 and KS-5 alone on the number of viable cells (b) and the percent of cell death (c) in KG-1a cell cultures following $72 \mathrm{~h}$ of incubation. (d,e,g,h) Effects of KS-3 and its analogs (5 $\mu \mathrm{M})$ and carnosic acid (CA), alone and in combination, on the number of viable cells (d, $\mathbf{g})$ and the percent of cell death (e,h) in KG-1a $(\mathbf{d}, \mathbf{e})$ and HL60 (g,h) cells $(72 \mathrm{~h})$. (f,i) Effects of the indicated KS-3 and its analogs $(5 \mu \mathrm{M})$ and CA, alone and in combination, on apoptosis (early+late) induction in KG-1a (f) and HL60 (i) cells ( $24 \mathrm{~h})$. The data are the means \pm SD $(n=3)$. \#, $p<0.05$, effect of a combination vs. sum of the effects of single agents $(n=5)$; Student's $t$ test.

As presented in Table 1, the estimated binding energy (BE) of the above complexes is 3-4 times stronger than that of the two water molecules (about $5 \mathrm{kcal} / \mathrm{mol}$ ). This suggests that, in aqueous solution, these putative complexes can be stable, and, perhaps, are able to reach and be transported into the cells in culture. The KS-3-CA complex exhibited the highest negative $\mathrm{BE}$ (Table 1), which correlated with the strongest cooperative cytotoxicity of the KS-3+CA combination, suggesting that this complex might be the most stable among the four analyzed complexes. In contrast, the one containing KS-7, the hydroxybenzylideneacetone counterpart of KS-3 (see Figure 1), forms relatively the weakest bond. It suggests that this complex can dissociate faster than other complexes in the presence of polar molecules, forming the nearest neighbor environment (e.g., the amino acid residues in the active site of the target enzyme or receptor). The negative BE of the KS-6-CA complex $(\sim-16 \mathrm{kcal} / \mathrm{mol})$ was found to be relatively low compared to that of the KS-3-CA complex ( -19 kcal/mol). Therefore, it appears that although KS-6 can cooperate with CA in inducing cytotoxicity, this putative complex is still less stable than KS-3-CA. 
(a)<smiles>C/C=C\C(=C/C=C/c1ccc(O)cc1)C(=O)OC</smiles>

MHB<smiles>COC(=O)c1ccc(O)cc1</smiles><smiles>CCCC(=O)OC</smiles>

MHMB<smiles>COC(=O)c1ccc(O)c(OC)c1</smiles>

(b)

KG-1a (72 h)

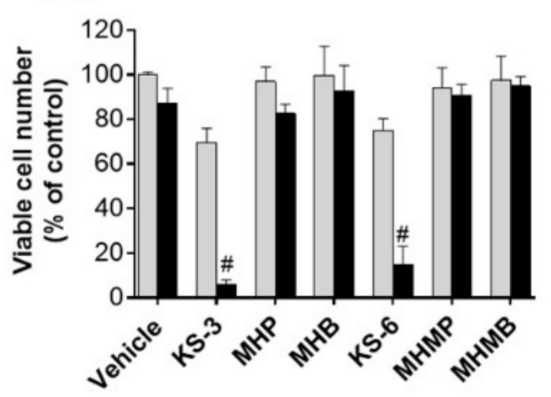

(c)

KG-1a (72 h)

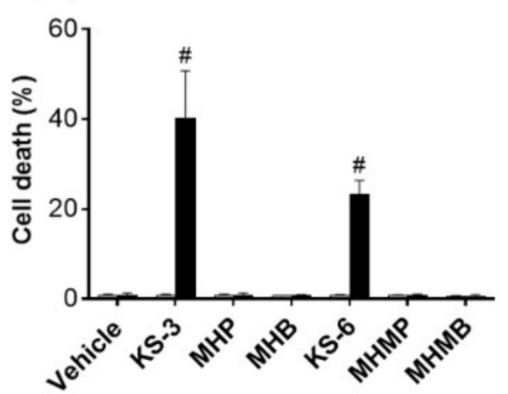

(d)

KG-1a (8 h)

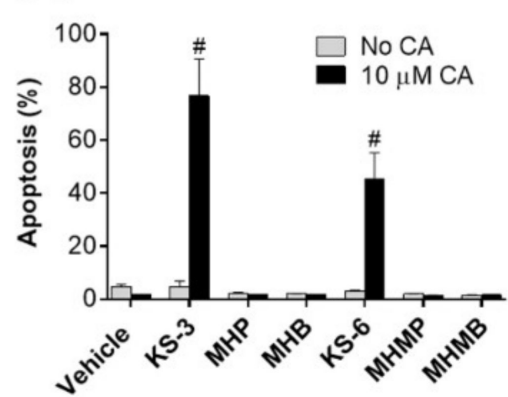

Figure 6. Cooperative activity of KS-3 and KS- 6 with CA depends on the C7-C 8 carbon-carbon double bond of the $\alpha$, $\beta$ unsaturated carbonyl moiety. (a) Molecular structures of KS-3, methyl 3-(4-hydroxyphenyl) propionate (MHP), methyl 4-hydroxybenzoate (MHB), KS-6, methyl 3-(3-hydroxy-4-methoxyphenyl) propanoate (MHMP) and methyl 3-hydroxy4-methoxy-benzoate (MHMB). KG-1a cells were cultured with the indicated phenolic compounds at $5 \mu \mathrm{M}$, carnosic acid (CA) at $10 \mu \mathrm{M}$, or their combinations, followed by the Trypan Blue exclusion assay (72 h; (b,c)) or the annexin V/7-AAD binding assay $(8 \mathrm{~h} ;(\mathbf{d}))$. (b,c) Effects of the indicated compounds on the number of viable cells (b) and the percent of cell death (c) in KG-1a cell cultures. (d) The extent of apoptosis (early + late) was determined by flow cytometry, and data are the means $\pm \operatorname{SD}(n=5)$. \#, $p<0.05$, effect of a combination vs. sum of the effects of single agents; Student's $t$ test.

Table 1. Binding energy of selected carnosic acid anion-hydroxycinnamic acid derivative molecular complexes.

\begin{tabular}{cc}
\hline Molecular Complex $^{\mathbf{a}}$ & ${\text { Binding Energy }[\mathbf{k c a l} / \mathbf{m o l}]^{\mathbf{b}}}^{\mathbf{b}}$ \\
Carnosic acid anion-KS-1 & -17 \\
Carnosic acid anion-KS-3 & -19 \\
Carnosic acid anion-KS-6 & -16 \\
Carnosic acid anion-KS-7 & -14 \\
Carnosic acid anion-KS-9 & -16 \\
\hline
\end{tabular}

a The full names of KS-1, KS-3, KS-6, KS-7 and KS-9 compounds are defined in the Experimental section. ${ }^{\mathrm{b}}$ Binding energies were calculated as described in the Experimental Section.

It is worth to note that the KS-CA complexes are bound by stacking interactions, although both components are polar molecules. Another interesting feature of these complexes is the strong interaction between the $-\mathrm{COO}^{-}$anionic group and the $\mathrm{OH}$-group on the CA component. It is likely that there exists some equilibrium, where the proton moves almost freely according to the following scheme:

$$
\mathrm{R}^{-} \mathrm{COO}^{-} \cdots \text { OH-R } \leftarrow \rightarrow \mathrm{R}-\mathrm{COOH}{ }^{\cdots}{ }^{-} \mathrm{O}-\mathrm{R}
$$

where $\mathrm{R}$ denotes remaining fragments of the CA molecule. Such a unique polar fragment of the CA molecule can interact in a unique way with the surrounding molecules of the environment. 
(a)

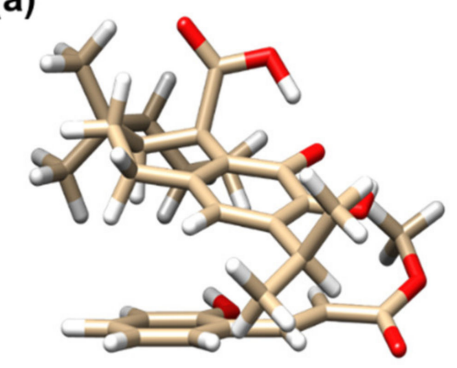

Carnosic acid anion --- KS-1 (b)

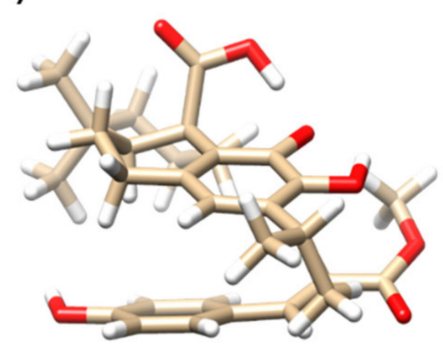

(c)

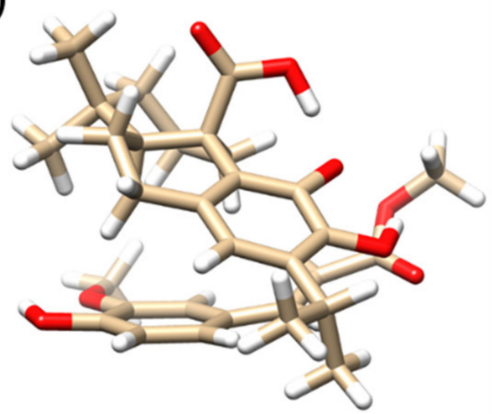

(d)

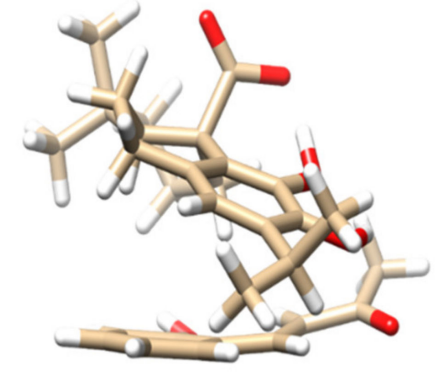

Carnosic acid anion --- KS-7 (e)

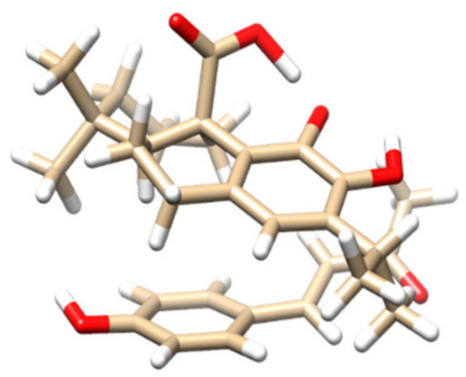

Carnosic acid anion --- KS-9

Figure 7. Molecular models of the complexes composed of the carnosic acid anion and selected KS compounds. The aromatic rings of the KS molecules are seen at the bottom of each complex (a-e). The carnosic acid anion is located above the aromatic ring of KS. The optimal structure of the carnosic anion in the complexes shows the intramolecular hydrogen bond - $\mathrm{COO}^{-}-$ $\mathrm{OH}$ in the form of $-\mathrm{COOH}-\mathrm{O}^{-}$as a result of proton transfer between oxygen atoms $($see $(\mathbf{a}-\mathbf{c}, \mathbf{e}))$. The white, gold and red colors correspond to hydrogen, carbon and oxygen atoms, respectively.

\subsection{Hydroxycinnamic Acid Derivatives Can Enhance the Differentiation of AML Cells Induced by Calcitriol}

AML is characterized by a differentiation block leading to accumulation of highly proliferative immature myeloid blasts. Therefore, differentiation-based therapy is a promising approach for AML treatment [41]. We have previously shown that (pro-)electrophilic polyphenols and drugs can enhance monocyte/macrophage differentiation of AML cells triggered by active vitamin $\mathrm{D}$ derivatives or other agents, without inducing cytotoxicity $[24,25,38]$.

Here we found that, while having no effect when applied alone for $96 \mathrm{~h}$, most HCADs, as well as pCouA and FerA, could also significantly potentiate, to a varying extent, the prodifferentiation effect of a low concentration of calcitriol ( $2.5 \mathrm{nM}$ ) in HL60 cell (Figure 8a,b) and U937 cells (Figure 8c,d). This is evidenced by significantly higher percentages of cells, double-positive to CD14 (a monocytic surface differentiation marker) and CD11b (a general myeloid marker), observed in combination-treated cells compared with the effect of calcitriol alone (Figure 8b,d). Notably, KS-3 and KS-6 were found to be significantly stronger differentiation enhancers than the other tested compounds (Figure 8b,d and Suppl. Table S2). On the other hand, MHP and MHMP, which lack the double C7-C8 carbon-carbon bond (Figure 6a), had no potentiating effects (Figure $8 b$,d). These results indicate that the potentiation of calcitriol-induced differentiation by pCouA, FerA and their derivatives is largely dependent on the presence of $\alpha, \beta$-unsaturated carbonyl and is stronger when HCADs also have a hydroxyl group at the para position of the phenolic ring and a methyl-esterified carboxyl group. 


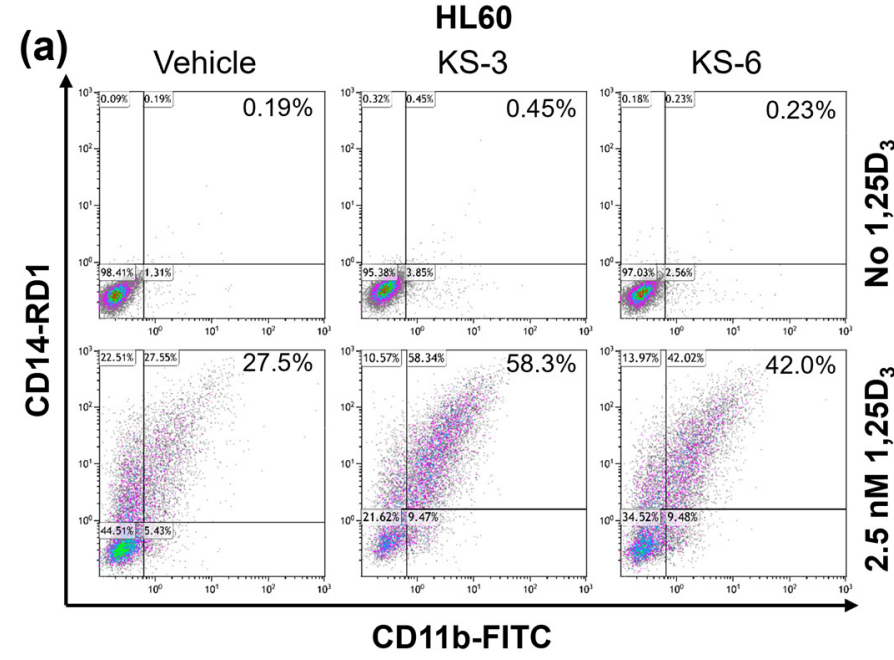

(c)

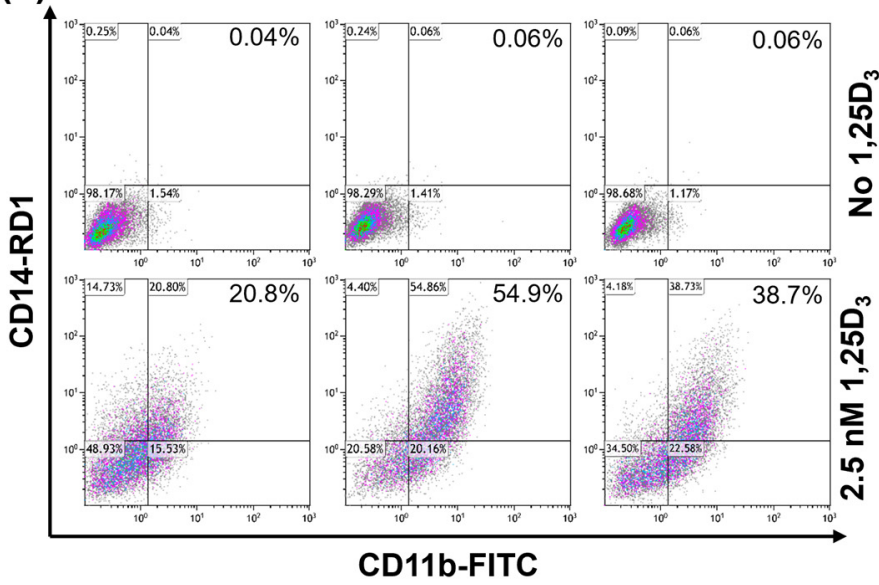

(b) HL60

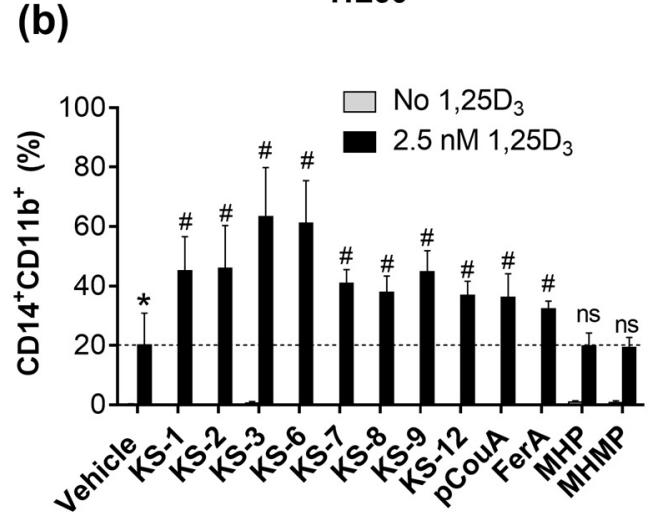

(d)

U937

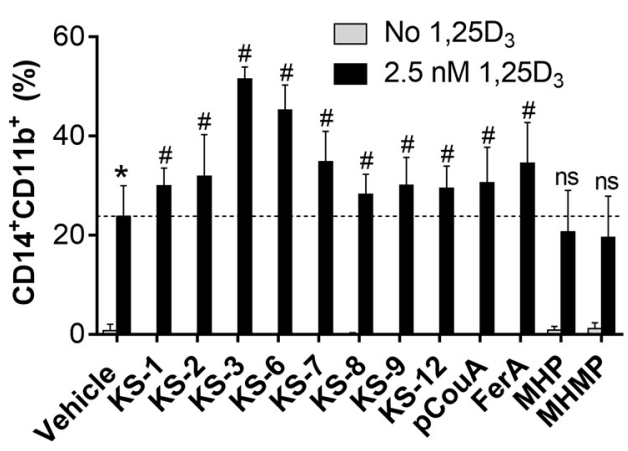

Figure 8. Hydroxycinnamic acids and their derivatives enhance the differentiation-inducing activity of calcitriol in AML cells. HL60 (a,b) and U937 (c,d) cells were treated with para-coumaric acid (pCouA), ferulic acid (FerA) or their derivatives $(5 \mu \mathrm{M})$, calcitriol $\left(1,25 \mathrm{D}_{3} ; 2.5 \mathrm{nM}\right)$ or their combinations, for $96 \mathrm{~h}$. Expression of surface myeloid differentiation markers was measured by flow cytometry. (a,c) Typical flow cytometric data obtained in representative experiments. The percentages of cells that are double-positive for CD14 and CD11b $\left(\mathrm{CD} 14^{+} \mathrm{CD} 11 \mathrm{~b}^{+}\right)$are shown in the upper right quadrants. (b,d) Averaged percentages of cells double-positive for CD14 and CD11b. The data are the means $\pm \operatorname{SD}(n=5) .{ }^{*}, p<0.05$ vs. vehicle. $\#, p<0.05$, effect of a combination vs. sum of the effects of single agents; Student's $t$ test; ns-non-significant.

We have previously reported that the enhancement of the pro-differentiation activity of vitamin D derivatives by electrophilic compounds containing an $\alpha, \beta$-unsaturated carbonyl (e.g., fumaric acid esters) or by CA, which is easily oxidized to an ortho-quinonetype electrophile [42], is attributed to the ability of these electrophiles to activate the transcription factor nuclear factor-erythroid factor 2-related factor 2 (Nrf2) [28,38]. We, thus, compared the effects of KS-3 and KS- 6 to those of MHP and MHMP on the protein expression of $\mathrm{NAD}(\mathrm{P}) \mathrm{H}$ :quinone oxidoreductase 1 (NQO1) and thioredoxin reductase 1 (TrxR1), the known Nrf2-responsive gene products [43,44]. As shown in Figure 9, the protein levels of NQO1 and, to a lesser extent, TrxR1 were significantly increased in HL60 cells treated with either KS-3 or KS-6 in the absence or presence calcitriol. In contrast, MHP or MHMP had only a minimal or no effect on the expression of these proteins. 
(a)

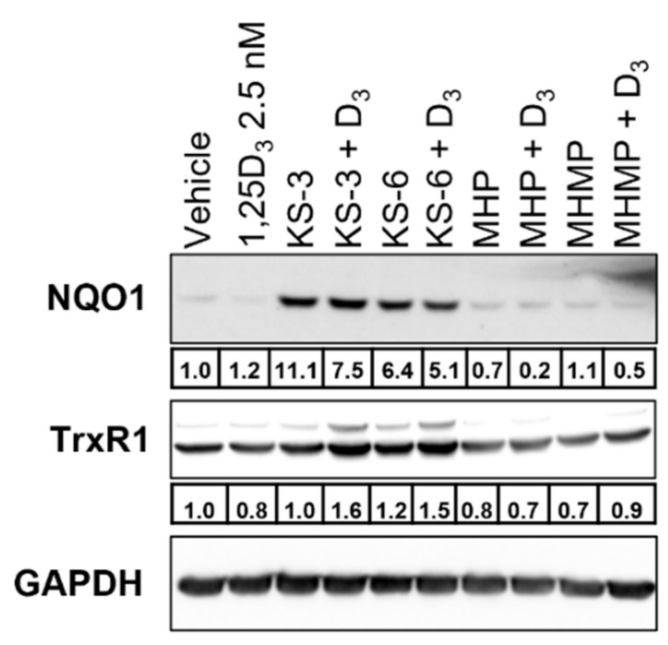

(b)
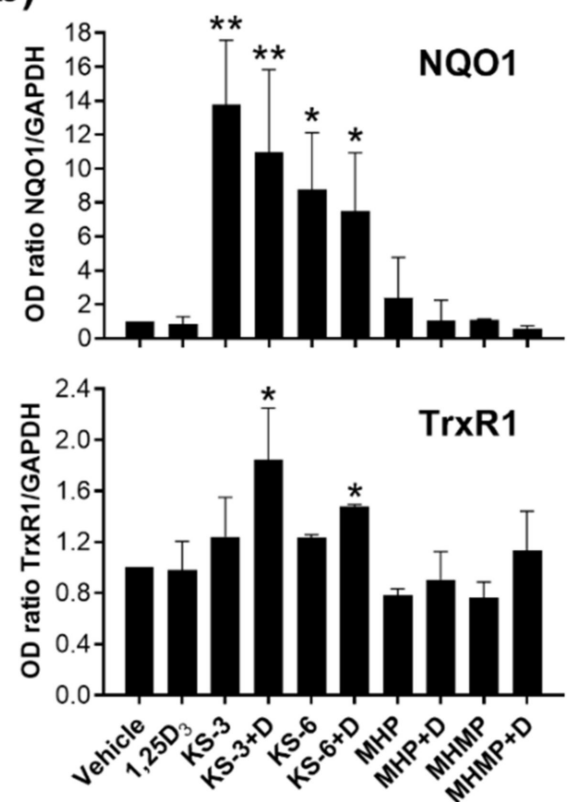

Figure 9. Induction of NQO1 and TrxR1 protein expression in HL60 cells treated with KS-3 or KS-6, but not with MHP or MHMP. Cells were incubated with the indicated phenolic compounds $(5 \mu \mathrm{M})$, calcitriol $\left(1,25 \mathrm{D}_{3}\right.$ or $\left.\mathrm{D}_{3} ; 2.5 \mathrm{nM}\right)$ or their combinations, for $48 \mathrm{~h}$. (a) NQO1 and TrxR1 protein expression analyzed by Western blotting. Integrated Density Values (IDVs) of the indicated protein bands normalized to IDVs of respective GAPDH bands are shown below corresponding blot images. Representative blots of three similar experiments are presented. (b) Averaged relative protein levels. The data are the means $\pm \operatorname{SD}(n=3) .{ }^{*}, p<0.05$ and ${ }^{* *}, p<0.01$ vs. vehicle.

\section{Discussion}

We have recently reported that, similar to curcumin, methyl 4-hydroxycinnamate (KS-3) can synergistically cooperate with CA at low, non-cytotoxic concentrations of each agent to kill AML cells [35]. In order to explore the chemical nature of this synergy, we characterized here the structure-activity relationship for coumaric and ferulic acids and their methyl ester and methyl ketone derivatives to cooperate with CA in inducing cytotoxicity. We also determined the structural requirements for these compounds to potentiate calcitriol-induced myeloid differentiation of AML cells.

One of the major novel findings of the present study is that synergistic HCAD/CA cooperation requires the following critical structural features of a HCAD: (a) the para position of the hydroxyl group on the phenolic ring, (b) the C7-C8 double bond and (c) the methyl-esterified carboxyl group. This conclusion is based on the evidence showing that, under otherwise equal conditions, the lack of any one of these features leads to the complete loss of HCAD/CA synergy in reducing viable cell numbers (Figure 2d,e), inducing apoptosis (Figures $2 \mathrm{f}$ and 4 ), and apoptosis-associated raising of cytosolic calcium levels (Figure 3) in AML cells. Interestingly, the presence of other chemical groups on the phenolic ring, in addition to the para hydroxyl group, was found to impair (KS-6) or even abolish (methyl caffeate or compounds KS-4 and KS-5) the capacity of an HCAD to cooperate with CA (Suppl. Figure S2, Figures 5 and 6). Collectively, these data support the notion that methyl 4-hydroxycinnamate (KS-3) is likely to represent an optimal HCAD structure required for effective synergistic cooperation with CA.

Although the precise roles of the above essential chemical properties of KS-3 in this synergy remain to be fully elucidated, each of these features was shown to be important for the biological effects of different agents. Particularly, phenolic compounds with a hydroxyl group in the para position were found to exhibit stronger biological activities, compared with similar molecules with hydroxyls at other positions. For instance, coumarins with 
para-hydroxyl groups demonstrated superior cytotoxic effects on several cancer cell lines, particularly, on AML (HL60) cells [45]. In addition, among twenty-one tested derivatives of resveratrol, the compounds with para-hydroxyl groups were shown to be the strongest tyrosinase inhibitors [46]. The importance of $\alpha, \beta$-unsaturated carbonyl groups in the anticancer effects of different agents has been explored in several studies. For example, following testing of twenty-seven known electrophilic and antioxidant compounds with drug-like properties it was found that $\alpha, \beta$-unsaturated carbonyl-containing agents were selectively cytotoxic to chronic lymphocytic leukemia cells, and that the loss of the $\alpha, \beta$ unsaturation abrogated this activity [47]. Also, the double bond of the $\alpha, \beta$-unsaturated carbonyl moiety of 15-keto prostaglandin E2 was found to be crucial for the inhibition of both STAT3 activation in breast cancer cells and breast tumor growth in a xenograft mouse model [48]. Methyl esterification of the carboxyl group in the phenolic amide javamide-I resulted in enhanced p53-dependent induction of cell death in THP-1 human AML cells [49]. In addition, methyl esterification of the melanin pigment 5,6-dihydroxyindole-2-carboxylic acid was shown to improve its antioxidant activity and photostability [50].

The fact that, when combined with CA, the same chemical structure (KS-3) most effectively promoted both apoptotic cell death (Figures $2 \mathrm{f}$ and 4 ) and elevation of cytosolic $\mathrm{Ca}^{2+}$ levels (Figure 3) further supports our previous findings that intracellular calcium mobilization by the KS-3+CA combination is essential for apoptosis induction in AML cells [35]. Studies of the molecular mechanism of HCAD/CA-induced disruption of the intracellular calcium homeostasis are in progress in this laboratory.

In silico analysis of the chemical interaction between the selected HCADs and CA by means of the molecular quantum mechanical modeling suggests that HCAD molecules can potentially form stable complexes with the $\mathrm{CA}$ anion. The binding energy varies between -14 and $-19 \mathrm{kcal} / \mathrm{mol}$ (Table 1 ) and is 3-4 times stronger than hydrogen bonds in water. Unique geometry of these complexes implies that the HCAD —CA species, particularly KS3-CA anion may bind, perhaps selectively, to certain cellular structures, e.g., regulatory proteins involved in the intracellular calcium homeostasis. The lower negative BE, i.e., lower stability, of the KS-6-CA complex compared to that of KS-3-CA correlates with a lower cytotoxic activity of the KS-6+CA combination. However, similar low BE values were also obtained for the non-active KS-1-CA or KS-9-CA complexes. This suggests that chemical stability of putative HCAD—CA species might play a lesser role in their biological activity than, e.g., the specific structures/conformations of the complexes.

Another important finding of this study is that KS-3 and KS-6 also exhibited superior abilities to potentiate the differentiation-inducing effect of calcitriol, applied at a low nanomolar concentration, as compared to the other HCADs, pCouA and FerA (Figure 8). These results indicate that the presence of the three key structural moieties in an HCAD molecule (the para position of the hydroxyl group on the phenolic ring, C7-C8 double bond and methyl ester modification of the carboxyl group) is essential. not only for the cooperation with CA to induce cell death, but, also, for its differentiation-enhancing capacity, although a major requirement for such potentiation appears to be the existence of the double bond (Figure 8 and Suppl. Table S2).

We have recently demonstrated that the transcription factor Nrf2 mediates the enhancing effect of CA on calcitriol-induced differentiation of AML cells and that other structurally distinct Nrf2 activators can also potentiate the differentiation-inducing effects of active vitamin $\mathrm{D}$ derivatives $[28,38]$. These effects were associated with upregulation of different Nrf2 target genes (NQO1, TrxR1 and glutamate-cysteine ligase) both at mRNA and protein levels $[27,28,38]$. By analogy, the ability to KS-3 and KS- 6 (which contain the $\alpha$, $\beta$-unsaturated carbonyl), but not MHP and MHMP (which lack this moiety), to upregulate NQO1 and TrxR1 protein levels (Figure 9) implies the involvement of the Nrf2 signaling pathway in the differentiation-enhancing effects of HCADs containing the C7-C8 carbon double bond. Phenolic acid derivatives, such as caffeic acid phenethyl ester and ethyl ferulate, were also found to activate Nrf2 [51]. Furthermore, it was shown that ethyl esters of ferulic and caffeic acid were capable of inducing differentiation of HL60 cells and 
enhancing the maturation stimulated by calcitriol [52]. As the presence of $\alpha, \beta$-unsaturated carbonyl moiety in various electrophilic compounds is crucial for their activation of the Nrf2/antioxidant response element signaling pathway [47,53-55], our present findings further support, though indirectly, the notion that Nrf2 activation by electrophilic phenolic compounds has a key role in the enhancement of calcitriol-induced differentiation of AML cells.

\section{Conclusions}

In conclusion, the findings presented here revealed the previously unknown chemical nature of the synergy between phenolic compounds in killing AML cells. Particularly, the structure-activity relationship analysis of HCADs resulted in the identification of key structural moieties of HCAD molecules that are critical for the synergy with CA in killing AML cells. Notably, the same structural features of HCADs were found to be important for the synergistic cooperation of HCADs and the active vitamin D metabolite calcitriol in inducing the enhanced differentiation of AML cells. The above findings may represent a novel approach for the rational design of synergistically acting AML drugs based on the prototype hydroxycinnamate-phenolic diterpene and hydroxycinnamate-calcitriol combinations tested in this study.

Supplementary Materials: The following are available online at https://www.mdpi.com/article/10 $.3390 /$ biomedicines $9111517 /$ s1, Figure S1: Comparison between the apoptosis-inducing effects of the combinations of KS-3 and KS-6 with carnosic acid, Figure S2: The additional 3-hydroxyl group on the phenolic ring of KS-3 (as in methyl caffeate) abolishes its ability to cooperate with carnosic acid, Table S1: The Cartesian coordinates of the carnosic acid anion-KS-x molecular complexes, Table S2: KS-3 and KS-6 enhance calcitriol-induced differentiation of AML cells significantly stronger than their chemical analogs.

Author Contributions: Conceptualization, A.T., K.S. and M.D.; Formal analysis, A.T. and A.L.; Funding acquisition, M.C. and M.D.; Investigation, A.T., S.A., S.M. and A.L.; Resources, K.S. and M.C.; Supervision, M.D.; Validation, A.T., K.S., S.A., S.M., A.L. and M.D.; Visualization, A.T. and A.L.; Writing—original draft, A.T., K.S. and M.D.; Writing—review and editing, A.T., K.S. and M.D. All authors have read and agreed to the published version of the manuscript.

Funding: This study was supported by the Israel Science Foundation grant 226/16 (to M.D.) and supported under the framework of a statutory project of the Łukasiewicz-Industrial Chemistry Institute (No 841333) funded by the Polish Ministry of Science and Higher Education.

Data Availability Statement: Data is contained within the article or Supplementary Material.

Acknowledgments: The authors thank Meitar Hertzman (Department of Clinical Biochemistry and Pharmacology, Ben-Gurion University of the Negev) for her valuable contribution to determining the effects of methyl caffeate on cell viability. The calculations were performed at the Interdisciplinary Centre for Mathematical and Computational Modeling of the University of Warsaw (ICM UW, the computer grant G18-6) which is kindly acknowledged for allocating facilities and computer time.

Conflicts of Interest: The authors declare no conflict of interest.

\section{References}

1. Newman, D.J.; Cragg, G.M. Natural Products as Sources of New Drugs over the Nearly Four Decades from 01/1981 to 09/2019. J. Nat. Prod. 2020, 83, 770-803. [CrossRef] [PubMed]

2. Mateen, S.; Raina, K.; Agarwal, R. Chemopreventive and anti-cancer efficacy of silibinin against growth and progression of lung cancer. Nutr. Cancer 2013, 65 (Suppl. 1), 3-11. [CrossRef] [PubMed]

3. Ko, J.H.; Sethi, G.; Um, J.Y.; Shanmugam, M.K.; Arfuso, F.; Kumar, A.P.; Bishayee, A.; Ahn, K.S. The Role of Resveratrol in Cancer Therapy. Int. J. Mol. Sci. 2017, 18, 2589. [CrossRef] [PubMed]

4. Almatroodi, S.A.; Almatroudi, A.; Khan, A.A.; Alhumaydhi, F.A.; Alsahli, M.A.; Rahmani, A.H. Potential Therapeutic Targets of Epigallocatechin Gallate (EGCG), the Most Abundant Catechin in Green Tea, and Its Role in the Therapy of Various Types of Cancer. Molecules 2020, 25, 3146. [CrossRef]

5. Giordano, A.; Tommonaro, G. Curcumin and Cancer. Nutrients 2019, 11, 2376. [CrossRef] 
6. Espinoza, J.L.; Kurokawa, Y.; Takami, A. Rationale for assessing the therapeutic potential of resveratrol in hematological malignancies. Blood Rev. 2019, 33, 43-52. [CrossRef]

7. Avtanski, D.; Poretsky, L. Phyto-polyphenols as potential inhibitors of breast cancer metastasis. Mol. Med. 2018, 24, 29. [CrossRef] [PubMed]

8. Borges, G.A.; Elias, S.T.; Amorim, B.; de Lima, C.L.; Coletta, R.D.; Castilho, R.M.; Squarize, C.H.; Guerra, E.N.S. Curcumin downregulates the PI3K-AKT-mTOR pathway and inhibits growth and progression in head and neck cancer cells. Phytother. Res. 2020, 3311-3324. [CrossRef]

9. Petiti, J.; Rosso, V.; Lo Iacono, M.; Panuzzo, C.; Calabrese, C.; Signorino, E.; Pironi, L.; Cartella, A.; Bracco, E.; Pergolizzi, B.; et al. Curcumin induces apoptosis in JAK2-mutated cells by the inhibition of JAK2/STAT and mTORC1 pathways. J. Cell Mol. Med. 2019, 23, 4349-4357. [CrossRef] [PubMed]

10. Mahmoud, N.; Saeed, M.E.M.; Sugimoto, Y.; Klinger, A.; Fleischer, E.; Efferth, T. Putative molecular determinants mediating sensitivity or resistance towards carnosic acid tumor cell responses. Phytomedicine 2020, 77, 153271. [CrossRef]

11. Steiner, M.; Priel, I.; Giat, J.; Levy, J.; Sharoni, Y.; Danilenko, M. Carnosic acid inhibits proliferation and augments differentiation of human leukemic cells induced by 1,25-dihydroxyvitamin D3 and retinoic acid. Nutr. Cancer 2001, 41, 135-144. [CrossRef] [PubMed]

12. Lopez-Jimenez, A.; Garcia-Caballero, M.; Medina, M.A.; Quesada, A.R. Anti-angiogenic properties of carnosol and carnosic acid, two major dietary compounds from rosemary. Eur. J. Nutr. 2013, 52, 85-95. [CrossRef] [PubMed]

13. Kikuchi, H.; Yuan, B.; Yuhara, E.; Imai, M.; Furutani, R.; Fukushima, S.; Hazama, S.; Hirobe, C.; Ohyama, K.; Takagi, N.; et al. Involvement of histone $\mathrm{H} 3$ phosphorylation via the activation of p38 MAPK pathway and intracellular redox status in cytotoxicity of HL-60 cells induced by Vitex agnus-castus fruit extract. Int. J. Oncol. 2014, 45, 843-852. [CrossRef] [PubMed]

14. Yang, C.W.; Chang, C.L.; Lee, H.C.; Chi, C.W.; Pan, J.P.; Yang, W.C. Curcumin induces the apoptosis of human monocytic leukemia THP-1 cells via the activation of JNK/ERK pathways. BMC Complement Altern. Med. 2012, 12, 22. [CrossRef]

15. Montane, X.; Kowalczyk, O.; Reig-Vano, B.; Bajek, A.; Roszkowski, K.; Tomczyk, R.; Pawliszak, W.; Giamberini, M.; MocekPlociniak, A.; Tylkowski, B. Current Perspectives of the Applications of Polyphenols and Flavonoids in Cancer Therapy. Molecules 2020, 25, 3342. [CrossRef]

16. Niedzwiecki, A.; Roomi, M.W.; Kalinovsky, T.; Rath, M. Anticancer Efficacy of Polyphenols and Their Combinations. Nutrients 2016, 8, 552. [CrossRef]

17. Maiti, P.; Plemmons, A.; Dunbar, G.L. Combination treatment of berberine and solid lipid curcumin particles increased cell death and inhibited PI3K/Akt/mTOR pathway of human cultured glioblastoma cells more effectively than did individual treatments PloS ONE 2019, 14, e0225660. [CrossRef]

18. Hu, W.H.; Chan, G.K.; Duan, R.; Wang, H.Y.; Kong, X.P.; Dong, T.T.; Tsim, K.W. Synergy of Ginkgetin and Resveratrol in Suppressing VEGF-Induced Angiogenesis: A Therapy in Treating Colorectal Cancer. Cancers (Basel) 2019, 11, 1828. [CrossRef] [PubMed]

19. Bulut, G.; Atmaca, H.; Karaca, B. Trastuzumab in combination with AT-101 induces cytotoxicity and apoptosis in Her2 positive breast cancer cells. Future Oncol. 2020, 16, 4485-4495. [CrossRef]

20. Srivastava, N.S.; Srivastava, R.A.K. Curcumin and quercetin synergistically inhibit cancer cell proliferation in multiple cancer cells and modulate Wnt/beta-catenin signaling and apoptotic pathways in A375 cells. Phytomedicine 2019, 52, 117-128. [CrossRef]

21. Santana-Galvez, J.; Villela-Castrejon, J.; Serna-Saldivar, S.O.; Cisneros-Zevallos, L.; Jacobo-Velazquez, D.A. Synergistic Combinations of Curcumin, Sulforaphane, and Dihydrocaffeic Acid against Human Colon Cancer Cells. Int. J. Mol. Sci. 2020, 21, 3108. [CrossRef] [PubMed]

22. Liu, Y.; Chang, R.L.; Cui, X.X.; Newmark, H.L.; Conney, A.H. Synergistic effects of curcumin on all-trans retinoic acid- and 1a,25-dihydroxyvitamin $\mathrm{D}_{3}$-induced differentiation in human promyelocytic leukemia HL-60 cells. Oncol. Res. 1997, 9, 19-29. [PubMed]

23. Nachliely, M.; Sharony, E.; Kutner, A.; Danilenko, M. Novel analogs of 1,25-dihydroxyvitamin $\mathrm{D}_{2}$ combined with a plant polyphenol as highly efficient inducers of differentiation in human acute myeloid leukemia cells. J. Steroid Biochem. Mol. Biol. 2015. [CrossRef] [PubMed]

24. Danilenko, M.; Wang, X.; Studzinski, G.P. Carnosic acid and promotion of monocytic differentiation of HL60-G cells initiated by other agents. J. Natl. Cancer Inst. 2001, 93, 1224-1233. [CrossRef] [PubMed]

25. Wang, Q.; Salman, H.; Danilenko, M.; Studzinski, G.P. Cooperation between antioxidants and 1,25-dihydroxyvitamin $\mathrm{D}_{3}$ in induction of leukemia HL60 cell differentiation through the JNK/AP-1/Egr-1 pathway. J. Cell Physiol. 2005, 204, 964-974. [CrossRef] [PubMed]

26. Sharabani, H.; Izumchenko, E.; Wang, Q.; Kreinin, R.; Steiner, M.; Barvish, Z.; Kafka, M.; Sharoni, Y.; Levy, J.; Uskokovic, M.; et al. Cooperative antitumor effects of vitamin $\mathrm{D}_{3}$ derivatives and rosemary preparations in a mouse model of myeloid leukemia. Int. J. Cancer 2006, 118, 3012-3021. [CrossRef] [PubMed]

27. Shabtay, A.; Sharabani, H.; Barvish, Z.; Kafka, M.; Amichay, D.; Levy, J.; Sharoni, Y.; Uskokovic, M.R.; Studzinski, G.P.; Danilenko, M. Synergistic antileukemic activity of carnosic acid-rich rosemary extract and the 19-nor Gemini vitamin D analogue in a mouse model of systemic acute myeloid leukemia. Oncology 2008, 75, 203-214. [CrossRef] [PubMed] 
28. Bobilev, I.; Novik, V.; Levi, I.; Shpilberg, O.; Levy, J.; Sharoni, Y.; Studzinski, G.P.; Danilenko, M. The Nrf2 transcription factor is a positive regulator of myeloid differentiation of acute myeloid leukemia cells. Cancer Biol. Ther. 2011, 11, 317-329. [CrossRef] [PubMed]

29. Wang, X.; Gocek, E.; Novik, V.; Harrison, J.S.; Danilenko, M.; Studzinski, G.P. Inhibition of Cot1/Tlp2 oncogene in AML cells reduces ERK5 activation and up-regulates p27Kip1 concomitant with enhancement of differentiation and cell cycle arrest induced by silibinin and 1,25-dihydroxyvitamin $\mathrm{D}_{3}$. Cell Cycle 2010, 9, 4542-4551. [CrossRef] [PubMed]

30. Pesakhov, S.; Nachliely, M.; Barvish, Z.; Aqaqe, N.; Schwartzman, B.; Voronov, E.; Sharoni, Y.; Studzinski, G.P.; Fishman, D.; Danilenko, M. Cancer-selective cytotoxic $\mathrm{Ca}^{2+}$ overload in acute myeloid leukemia cells and attenuation of disease progression in mice by synergistically acting polyphenols curcumin and carnosic acid. Oncotarget 2016, 7, 31847-31861. [CrossRef] [PubMed]

31. Pesakhov, S.; Khanin, M.; Studzinski, G.P.; Danilenko, M. Distinct combinatorial effects of the plant polyphenols curcumin, carnosic acid, and silibinin on proliferation and apoptosis in acute myeloid leukemia cells. Nutr. Cancer 2010, 62, 811-824. [CrossRef] [PubMed]

32. El-Seedi, H.R.; El-Said, A.M.; Khalifa, S.A.; Goransson, U.; Bohlin, L.; Borg-Karlson, A.K.; Verpoorte, R. Biosynthesis, natural sources, dietary intake, pharmacokinetic properties, and biological activities of hydroxycinnamic acids. J. Agric. Food Chem. 2012, 60, 10877-10895. [CrossRef] [PubMed]

33. Abotaleb, M.; Liskova, A.; Kubatka, P.; Busselberg, D. Therapeutic Potential of Plant Phenolic Acids in the Treatment of Cancer. Biomolecules 2020, 10, 221. [CrossRef] [PubMed]

34. Su, P.; Shi, Y.; Wang, J.; Shen, X.; Zhang, J. Anticancer agents derived from natural cinnamic acids. Anticancer Agents Med. Chem. 2015, 15, 980-987. [CrossRef] [PubMed]

35. Trachtenberg, A.; Muduli, S.; Sidoryk, K.; Cybulski, M.; Danilenko, M. Synergistic Cytotoxicity of Methyl 4-Hydroxycinnamate and Carnosic Acid to Acute Myeloid Leukemia Cells via Calcium-Dependent Apoptosis Induction. Front Pharmacol. 2019, 10, 507. [CrossRef] [PubMed]

36. Sidoryk, K.; Jaromin, A.; Filipczak, N.; Cmoch, P.; Cybulski, M. Synthesis and Antioxidant Activity of Caffeic Acid Derivatives. Molecules 2018, 23, 2199. [CrossRef] [PubMed]

37. Danilenko, M.; Wang, Q.; Wang, X.; Levy, J.; Sharoni, Y.; Studzinski, G.P. Carnosic acid potentiates the antioxidant and prodifferentiation effects of $1 \alpha, 25$-dihydroxyvitamin $\mathrm{D}_{3}$ in leukemia cells but does not promote elevation of basal levels of intracellular calcium. Cancer Res. 2003, 63, 1325-1332. [PubMed]

38. Nachliely, M.; Trachtenberg, A.; Khalfin, B.; Nalbandyan, K.; Cohen-Lahav, M.; Yasuda, K.; Sakaki, T.; Kutner, A.; Danilenko, M. Dimethyl fumarate and vitamin D derivatives cooperatively enhance VDR and Nrf2 signaling in differentiating AML cells in vitro and inhibit leukemia progression in a xenograft mouse model. J. Steroid Biochem. Mol. Biol. 2019, 188, 8-16. [CrossRef] [PubMed]

39. Frisch, M.J.; Trucks, G.W.; Schlegel, H.B.; Scuseria, G.E.; Robb, M.A.; Cheeseman, J.R.; Scalmani, G.; Barone, V.; Petersson, G.A.; Nakatsuji, H.; et al. Gaussian 09, Revision D.01; Gaussian, Inc.: Wallingford, CT, USA, 2013; Available online: http: / / www.gaussian.com (accessed on 6 August 2021).

40. Foresman, J.B.; Frisch, Æ. Exploring Chemistry with Electronic Structure Methods, 3rd ed.; Gaussian, Inc.: Wallingford, CT, USA, $2015 ;$ p. 500.

41. Madan, V.; Koeffler, H.P. Differentiation therapy of myeloid leukemia: Four decades of development. Haematologica 2021, 106, 26-38. [CrossRef] [PubMed]

42. Satoh, T.; McKercher, S.R.; Lipton, S.A. Nrf2/ARE-mediated antioxidant actions of pro-electrophilic drugs. Free Radic. Biol. Med. 2013, 65, 645-657. [CrossRef] [PubMed]

43. Nioi, P.; McMahon, M.; Itoh, K.; Yamamoto, M.; Hayes, J.D. Identification of a novel Nrf2-regulated antioxidant response element (ARE) in the mouse NAD(P)H:quinone oxidoreductase 1 gene: Reassessment of the ARE consensus sequence. Biochem. J. 2003, 374, 337-348. [CrossRef]

44. Sakurai, A.; Nishimoto, M.; Himeno, S.; Imura, N.; Tsujimoto, M.; Kunimoto, M.; Hara, S. Transcriptional regulation of thioredoxin reductase 1 expression by cadmium in vascular endothelial cells: Role of NF-E2-related factor-2. J. Cell Physiol. 2005, 203, 529-537. [CrossRef]

45. Gacche, R.N.; Jadhav, S.G. Antioxidant Activities and Cytotoxicity of Selected Coumarin Derivatives: Preliminary Results of a Structure-Activity Relationship Study Using Computational Tools. J. Exp. Clin. Med. 2012, 4, 165-169. [CrossRef]

46. Ismail, T.; Shafi, S.; Srinivas, J.; Sarkar, D.; Qurishi, Y.; Khazir, J.; Alam, M.S.; Kumar, H.M. Synthesis and tyrosinase inhibition activity of trans-stilbene derivatives. Bioorg. Chem. 2016, 64, 97-102. [CrossRef] [PubMed]

47. Wu, R.P.; Hayashi, T.; Cottam, H.B.; Jin, G.; Yao, S.; Wu, C.C.; Rosenbach, M.D.; Corr, M.; Schwab, R.B.; Carson, D.A. Nrf2 responses and the therapeutic selectivity of electrophilic compounds in chronic lymphocytic leukemia. Proc. Natl. Acad. Sci. USA 2010, 107, 7479-7484. [CrossRef]

48. Lee, E.J.; Kim, S.J.; Hahn, Y.I.; Yoon, H.J.; Han, B.; Kim, K.; Lee, S.; Kim, K.P.; Suh, Y.G.; Na, H.K.; et al. 15-Keto prostaglandin E2 suppresses STAT3 signaling and inhibits breast cancer cell growth and progression. Redox Biol. 2019, 23, 101175. [CrossRef] [PubMed]

49. Park, J.B. Javamide-I-O-methyl ester increases p53 acetylation and induces cell death via activating caspase 3/7 in monocytic THP-1 cells. Phytomedicine 2016, 23, 1647-1652. [CrossRef] [PubMed] 
50. Micillo, R.; Iacomino, M.; Perfetti, M.; Panzella, L.; Koike, K.; D’Errico, G.; d'Ischia, M.; Napolitano, A. Unexpected impact of esterification on the antioxidant activity and (photo)stability of a eumelanin from 5,6-dihydroxyindole-2-carboxylic acid. Pigment Cell Melanoma Res. 2018, 31, 475-483. [CrossRef]

51. Scapagnini, G.; Vasto, S.; Abraham, N.G.; Caruso, C.; Zella, D.; Fabio, G. Modulation of Nrf2/ARE pathway by food polyphenols: A nutritional neuroprotective strategy for cognitive and neurodegenerative disorders. Mol. Neurobiol. 2011, 44, $192-201$. [CrossRef] [PubMed]

52. Sokoloski, J.A.; Shyam, K.; Sartorelli, A.C. Induction of the differentiation of HL-60 promyelocytic leukemia cells by curcumin in combination with low levels of vitamin D3. Oncol. Res. 1997, 9, 31-39.

53. de Freitas Silva, M.; Pruccoli, L.; Morroni, F.; Sita, G.; Seghetti, F.; Viegas, C.; Tarozzi, A. The Keap1/Nrf2-ARE Pathway as a Pharmacological Target for Chalcones. Molecules 2018, 23, 1803. [CrossRef] [PubMed]

54. Shin, J.W.; Chun, K.S.; Kim, D.H.; Kim, S.J.; Kim, S.H.; Cho, N.C.; Na, H.K.; Surh, Y.J. Curcumin induces stabilization of Nrf2 protein through Keap1 cysteine modification. Biochem. Pharmacol. 2020, 173, 113820. [CrossRef] [PubMed]

55. Zhu, Y.; Wang, P.; Zhao, Y.; Yang, C.; Clark, A.; Leung, T.; Chen, X.; Sang, S. Synthesis, evaluation, and metabolism of novel shogaol derivatives as potent Nrf2 activators. Free Radic. Biol. Med. 2016, 95, 243-254. [CrossRef] [PubMed] 